\title{
Does DeterRence CHANGE PREFERENCES? EVIDENCE From a NATURAL EXPERIMENT
}

\author{
Elisa Cavatorta* and Ben Groom ${ }^{\dagger}$
}

April 18, 2020

\begin{abstract}
The deterrent effects of counter-violence initiatives could backfire if they cause preferences to change so that the perceived gains from violent actions increase. We test the preference-change hypothesis in a quasi-experimental design exploiting the random location of segments of the wall between the West Bank and Israel, an initiative intended to deter armed resistance. We undertake incentivized decision tasks with Palestinians to measure key individual traits that determine the valuation of political actions: preferences for risk, uncertainty and time delay. We show that people living close to the wall become more risk-tolerant, ambiguity averse and impatient than those unexposed to the wall, and this effect is amplified for people both exposed to and isolated (from the West Bank) by the wall. Preference-change could explain how repressive initiatives appear to perpetuate cycles of violence and resistance.
\end{abstract}

*Elisa Cavatorta: Department of Political Economy, King's College London, Strand, London WC2R 2LS and Institute for Fiscal Studies, 7 Ridgmount Street London WC1E 7AE; e-mail: elisa.cavatorta@kcl.ac.uk.

${ }^{\dagger}$ Ben Groom: Department of Geography and Environment, London School of Economics, Houghton Street, London WC2A 2AE, e-mail: b.groom@lse.ac.uk. We would like to thank participants in seminars and conferences at DIW Berlin, Maastricht, European Economic Association annual meeting, Essex, Karlsruhe, IMEBESS, FUR 2014 and Verein für SocialPolitik 2014, Innsbruck, WZB Berlin for stimulating discussions. We received helpful comments from Antonio Guarino, Shaun Hargreaves-Heap, George L, Ron Smith, David Schröder, Israel Waichman, Moti Michaeli, Philipp Reiss, Erwin Bulte, Steffen Huck, Orazio Attanasio and two anonymous referees. The authors are grateful to Haneen Ghazawneh and Aysheh Alawi for excellent assistance throughout the study and Farida, Fofo, Reem, Samah and Arwa for the data collection. Elisa Cavatorta gratefully acknowledges the support of the AXA Research Fund. This fieldwork has benefited from a financial grant from the Global Development Network-Economic Research Forum and a faculty grant from the School of Oriental and African Studies, University of London. The contents and recommendations do not necessarily reflect the views of the Global Development Network-Economic Research Forum. The responsibility for any errors or omissions is our own. 
Strategies to deal with conflict in cross-border disputes are traditionally based on the principle of deterrence. Many counter-insurgency (counter-terrorism and more generally counter-violence) initiatives aim to deter violent acts by increasing the costs or reducing the perceived payoffs from committing them 1 The logic behind these initiatives is supported by the host of game-theoretic models used in the political science and international relations literature. The cornerstone assumption of these models is that actors decide whether to engage in an action (wage war/engage in armed action/insurge) if the discounted net gain from the action is greater than that of inaction (or some other action). In short, observed actions are goal-orientated and the outcome of either rational choice or a well-defined behavioural economic model 2

By this argument, the decision to participate in aggressive action depends on how the perpetrators evaluate the pros and cons. The perceived gains are evaluated based on a set of preferences, the most important of which are the attitudes over risk, uncertainty and temporal trade-offs. There is a risk of failure in performing an act of aggression as well as uncertainty over the chances of success or failure $\mathrm{H}^{3}$ Actors must also trade-off present and future benefits and costs. The costs of aggression now may

\footnotetext{
${ }^{1}$ Fines for speeding provide a deterrent, as do traffic calming measures. Both increase the costs of speeding, but only the latter by physical means. Our definition of deterrence includes both types of policy.

${ }^{2}$ From hereon we use the term "rational agent" or "rationality" to refer to a utility maximizing agent. Such agents could also be subject to bounded rationality or the biases commonly described in behavioral economics.

${ }^{3}$ Risk refers to situations in which the possible outcomes are known along with their probabilities. An uncertain situation is one where the possible outcomes and probabilities are unknown. As in decision-theory, we refer to uncertainty about the probability distribution of (known) outcomes as 'ambiguity'. E.g. betting on the toss of a coin is a situation of risk, since the probabilities are well defined. Betting on whether a black or white ball will be drawn from an urn when the proportions of each are unknown is a decision under ambiguity, since the probabilities are unknown. Risk and ambiguity preferences are theoretically distinct and experimental evidence suggests they are uncorrelated (e.g. Levy et al., 2010, Cohen, Tallon and Vergnaud, 2011). Decisions under risk and ambiguity also seem to activate separate neural systems (Huettel et al., 2006).
} 
only reap benefits or punishments in the future, and future net benefits are typically discounted. Put differently, these preferences govern the valuation of the net gains, which in turn determines the final decision towards action versus inaction. The deterrence argument is based on preferences being stable and remaining unchanged over time, and goes like this: given a set of preferences, set the deterrent-policy in such a way that the perceived net gain from committing an aggressive action is lower than that of inaction, and the rational actor will refrain from the action. Aggression is thereby deterred and the objectives of the policy-maker are met.

Our results highlight the possibility of a fundamental flaw in this argument. Consider the possibility that the policy, originally intended as a deterrent-policy, changes the way the affected actors evaluate the costs and benefits of committing any given aggressive action. In other words, rather than being stable, the policy changes the preferences which govern the actors' decisions. $4^{4}$ An agent whose preferences are changed by a policy will evaluate the same action differently after the policy compared to before, resulting in a different appraisal of the overall net gain of committing the action. As a result, the same deterrent will not work in the expected way. Indeed, it may not work at all. To illustrate the point, suppose an actor is indifferent between committing violent action or not. A deterrent policy is introduced and it changes her risk preferences so that she becomes more risk tolerant (we will explain later why this may be the case). With these new preferences, the risk inherent in taking a violent action now weighs less in the overall calculation of the net gains. Even though the cost of committing the action may be increased by the imposed deterrent policy, the actor's appraisal of the net gain of being violent

\footnotetext{
${ }^{4}$ By preferences and 'preference change' we refer to fundamental attitudinal traits, rather than temporary 'expressed decisions' which may have been influenced by transitory stimuli, such as framing or the emotional state of the respondent at the time.
} 
may now be perceived greater than not being violent. Violent action might actually increase. The policy has yielded a counter-productive outcome: more violence rather than less, because the preferences which guide decisions have changed.

Empirical observations indeed suggest that deterrence does not always work. At the macro-level, it is observed that hostile initiatives often invite more resistance, locking countries into conflict-traps: e.g. increased military spending Collier et al., 2003), political repression and indiscriminate violence (Walter, 2004; Kalyvas, 2004). Micro-level studies suggest that when repression is used it invokes more violence rather than deterring it, fomenting violent extremism (Canetti-Nisim et al., 2009, Canetti et al., 2013), harnessing intra-group retaliation (Zeitzoff, 2014), inciting hate and inducing mobilization (De Mesquita, 2005). We argue that changes in preferences can cause these political behaviors. Violent actions are characterized by risk, uncertainty and temporal trade-offs, making preferences for risk, uncertainty and time discounting particularly important for decision making. Although preferencechange provides a clear mechanism for the failure of deterrence, this mechanism is seldom tested because preferences are usually unobserved. Our approach overcomes this problem. The deterrent initiative that we analyze is the construction of the barrier wall between Israel and the West Bank. This initiative was originally intended to deter aggressive actions by the targeted population. We show that the location of the wall can be treated as a natural experiment which randomly separates the Palestinian populations of interest. We collected original data from incentivized decision tasks that elicit preferences for risk, uncertainty and time delay, which then form the basis of a direct test of preference change. We exploit the natural experiment of the wall by collecting individual preference data in villages either side of the wall, and with no wall. These data allow us to identify causal evidence in the field of the 
existence of unintended effects of initiatives based on the principle of deterrence. We show that the policy of the wall changes the preferences of affected Palestinians by making them more risk tolerant, impatient and averse to uncertainty. We argue that such changes occur because the wall generates anger and resentment, and that they may lead to counter-productive outcomes and prolongation of conflict.

Our research design tackles the identification of causal effects by using the exact location of sections of the wall between the State of Israel and the West Bank region of the Palestinian territories. We exploit the fact that the wall runs inside the Palestinian territories, its final location was largely unknown beforehand and that, in some areas, the wall construction halted for reasons external to the characteristics of the local population. Indeed, sometimes the precise location of the wall changed accidentally, unexpectedly leaving Palestinian villages either side of the wall or in some instances literally dividing the same village into two parts. Furthermore, because of a stringent residence permit regime, people hardly move from the areas isolated by the wall. These conditions, random and unexpected separation and limited migration, make the division of villages by the wall a natural experiment (Dunning, 2012), which provides as-if random allocation of people into two treatment conditions: (i) close to the wall in areas isolated between the wall and the border with Israel; and (ii) close to wall in areas not isolated from the West Bank. The difference between the two treated groups is the intensity of treatment: in group (i) the wall creates physical isolation from the West Bank which is not present in group (ii). Palestinians in villages located equally close to the border but where the wall is not yet built represent a control group that allows us to measure the impact of the initiative on Palestinians affected by the wall.

We collect original micro-level data on individual preferences from people in 
treatment and control villages. We undertake incentivized decision tasks (using real money) that reveal information on individual risk, uncertainty and time preferences. The use of incentivized decision-tasks has two key advantages. First, they provide incentive-compatible tools for people to reveal their true preference traits. This makes the measurement more reliable relative to self-reported attitudes elicited in survey-type questions. Second, because every subject faces the same constraints and incentives in the tasks, they help overcome the challenges of isolating changes in preferences from other confounding factors, such as information, costs and resource constraints, which one has to face when focusing on behavioral outcomes or opinions, such as participation in protests and forms of political activism.

Our results show that individuals close to the wall are more risk tolerant, ambiguity averse and impatient compared to the unexposed controls living in villages without the wall. The impact on preferences is larger for those in isolated villages, indicating an impact on preferences that increases with the intensity of the physical constraints the wall imposes. We show that these changes are associated with the emotional response to the policy in accordance with social psychology theories: exposure to the wall invokes anger which leads to greater risk tolerance and impatience. A taste for risk and myopia is likely to increase the valuation of gains achieved by aggressive actions. Indeed, observational data from survey polls tends to support this argument, since the same population in which we observe changes in preferences also show more support for armed action against Israel.

As the first to study the impact of deterrence on preferences, this paper makes three contributions to the existing scholarly debate. First, by directly testing the effect on preferences (rather than behavior), we provide a possible new explanation for the existence of "rational" conflict traps. Retaliatory violence may persist 
if preferences change in a way that favours the valuation of perceived gains from attacking. Uncovering the effect on preferences is also important to understand behavior in conflict resolution and negotiations of peace agreements. Peace treaties involve immediate costs and later benefits. If people become more concerned with the present, then this changes the set of acceptable trade-offs between present and future costs and benefits. This may reduce the acceptable range of proposals based on the individual analysis of costs and benefits. Similarly, increases in aversion to uncertainty (ambiguity aversion) may influence the willingness to engage in negotiations, which have inherently uncertain outcomes. Ambiguity aversion also tends to reduce trust, leading to negative expectations about the future behaviour of others (Li, Turmunkh and Wakker, 2019; Rohner, Thoenig and Zilibotti, 2013). In the context of conflict, a lack of trust may perpetuate the cycle of violence by prompting defensive behaviour as retaliation or pre-emptive violent acts to deter the opponent.5 Secondly, to our knowledge, our work is a first in providing causal and field evidence in support for recent theoretical work of counter-terrorism arguing that tough policies have an undesirable provocation effect, alongside their deterrence (Dietrich, 2014; Rosendorff and Sandler, 2004). The efficacy of tough policies depends on the trade-off between deterrence and provocation. Our evidence on changing preferences and anecdotal evidence on increased support for armed action show empirical support for the role of provocation via a change in preferences.

Third, we link the rational choice theory with insights from the social psychology

\footnotetext{
${ }^{5}$ While this study is the first to look at the impact of deterrence policies on preferences, there are a few other studies that analyze the impact of very different exogenous events on preferences. The events analyzed include (a) natural disasters (Cassar, Healy and Von Kessler, 2017; Cameron and Shah, 2015); b) victimization (Moya, 2018, Kim and Lee, 2014); (c) distress from sudden financial hardship (Malmendier and Nagel, 2011: Cohn et al., 2014); (d) exposure to violence from an enemy during war (Voors et al. , 2012). These studies bring evidence of different impacts on preferences. In section 6 we propose a theoretical conjecture that may reconcile the apparently conflicting results of the existing body of evidence.
} 
literature to provide a framework with which to interpret the possible unexpected effects of deterrent policies. In particular, we highlight the importance of the role of emotions in changing the calculations of net gains from action: we show that a deterrent-policy which generates anger and resentment in the affected population produces changes in preferences in accordance with the social psychology theories of Reactance (Brehm and Brehm, 1981) and Appraisal Tendency Framework (Lerner and Keltner, 2000).$^{6}$ These changes may be detrimental for the relationship between the two countries.

\section{Background to the wall in the West Bank}

The wall in the Palestinian territories is the most visible sign of the protracted Palestinian-Israeli conflict. Following a series of suicide attacks on Israeli citizens during the Second Intifada, in 2002 the Israeli government began the construction of the 'barrier', a wall separating the West Bank from the State of Israel. The official rational to erect the wall is one of deterrence: preventing Palestinians without permits from entering Israel through open areas. The wall was built within the Palestinian territories of the West Bank, i.e. east of the 1949 Armistice Line (the Green Line) that divides the Israeli administration from that of the Palestinian territories. As a result, a number of communities (approximately 9,000 West Bank Palestinians at the time of the study) became cut off from the West Bank mainland and are de facto isolated between the Green Line and the wall (i.e. on the west side of

${ }^{6}$ Our findings on the importance of the role of emotions resonate with the focus of study by Callen et al. (2014) who analyze the effect of recollection of fearful events on risk preferences among Afghans. However, they use an ad-hoc design (which is discussed in Vieider (2018)) and no emotional recollection of anger, thus it is difficult to draw comparisons between our studies. 
the wall, loosely speaking on the 'Israeli side' of the wall)..$^{7}$ The Green Line is shown on the map in Figure B.1 (in Supplementary Material) by the black line and the wall's route is shown by the solid red line. Certain segments of the wall stray as much as $5 \mathrm{~km}$ inland from the Green Line. These 'enclave' areas between the Green Line and the wall are considered military zones and their Palestinian residents are subject to a number of movement restrictions. They are prohibited to enter Israel, although they reside on the 'Israeli side' of the wall, and must pass through checkpoints along the wall and undergo often lengthy security checks to reach services, such as medical care, markets and schools, located in the West Bank mainland, east of the wall. Access to these communities is prohibited to any Palestinian who resides in the West Bank mainland. For these reasons, these communities between the Green Line and the wall are de facto isolated from the West Bank interior.

The restrictions on movement harm Palestinians on both sides of the wall: for businesses in the enclaves, the checkpoints increase transport costs, reduce opportunities to market their products in the West Bank and reduce the supply of inputs and materials coming from the West Bank. For Palestinians landowners in the West Bank mainland, the restrictions of movement to the enclaves impede access to, and use of, farmland located between the Green Line and the wall. According to B'Tselem, 10 percent of the cultivated farmland of the West Bank is isolated in the enclaves (B'Tselem, 2012; World Bank, 2008). A number of reports from international organizations testify to how the wall has significantly affected people's lives in otherwise very similar communities and livelihoods. (OCHA, 2009a, 2011).

At the time of the study (July-October 2012), not all segments of the wall have

\footnotetext{
7The term 'West Bank Palestinians' refers to Palestinians with a West Bank ID, rather than Palestinians with Israeli passports or Jerusalem IDs, who are subject to the Israeli authority and enjoy different freedom of mobility.
} 
been built. There are areas nearby the Green Line which remain without wall. This is the case in some bordering areas in the southern part of the West Bank (south of Jerusalem), where there exist Palestinian communities in close proximity to the Green Line that do not have first-hand experience of the wall (see Figure B.1.$^{8}$ Israeli newspapers, B'Tselem and personal interviews with the authors evidenced that the construction of the wall was planned in these areas similarly to the other areas but that eventually did not materialize. It is documented that financial issues constrained the completion of these segments of the wall despite Israel security apparatus stating that the construction of the wall in that area was "a vital security need" ? The area also comprises historic sites (e.g. the ruins of the city of Betar, the last bastion of the Bar Kochba rebellion against the Romans) and iconic agricultural terraces which were recognized by UNESCO as a World Heritage Site in 2014. At the time of the data collection, there was a pending legal case brought forward by the Israeli Nature and Parks Authority, and other Israeli and Palestinian organizations (separately, of course), to preserve the environmental and cultural heritage of the historical sites. The outcome of the legal case - which froze the planned construction

\footnotetext{
${ }^{8}$ The distance of these communities which are not exposed to the wall is comparable to the distance from the Green Line of other communities where the wall does exist.

${ }^{9}$ In reference to the segments of the wall in the control areas, an article in the Guardian on 11th May 2011 writes "A defence ministry document, revealed by Army Radio, says work near a group of settlements known as Gush Etzion [control area] has been frozen but is expected to resume at the end of next year [2012]." "Army Radio quoted the defence ministry document as saying Israel "realises the importance of erecting the fence and retains all of the claims to its construction despite a lack of funding'. The cost of the barrier is thought to have risen considerably since it was estimated to be about USD 3.5bn (GBP 2.1bn) five years ago." https : //www.theguardian.com/world/2011/may/11/israel - west - bank - barrier On another article, Haaretz 4th January 2015 https : //www.haaretz.com/.premium - palestinians israelis - laud-s-court-decision - 1.5356139, while reporting about contradictory statements by the Ministry of Defence at the time, evidenced that Israel's long-held position was that security needs were equally high in the area. The article writes: "[The Israeli High Court President] Grunis wrote, 'Inasmuch as the state contended throughout the various stages of proceedings that there was a vital security need to construct the barrier along a route next to Battir [one of the control villages], at this point the defense minister position is that building the separation barrier along this route (while stressing its security importance) is not of a priority that would justify building it at this time' [January 2015]."
} 
- arrived only in January 2015 (well after the end of data collection) and until

that point the exact location of the wall and its timing remained uncertain to the Palestinian residents of those areas. ${ }^{10}$ The wall's projected route (as it is conjectured by international organizations as no official map exists) is shown by the dotted red line in map B.1 (OCHA, 2011).

Based on their location with respect to the wall, we label these three groups of localities as follows: group (i) exposed to and isolated from the West Bank mainland by the wall (they are located between the Green Line and the wall); group (ii) exposed to and not isolated from the mainland and group (iii) without wall (but similarly close the Green Line). Qualitative and quantitative evidence indicates that the wall's route appears unrelated to Palestinian characteristics and there is no evidence of selection bias due to individual differences prior to the building of the wall. We present this evidence in detail in Section 4 .

\section{The wall and preference change}

The objective of this study is to test whether the imposition of the barrier wall can affect the way in which people make decisions by changing their underlying preferences for risk, ambiguity and time delay. The wall can be conceived of as a repressive initiative and a deterrent policy. We argue that the wall induces more risk tolerant, ambiguity averse and impatient preferences, which could undermine

\footnotetext{
${ }^{10}$ In an article on 18 October 2012 for example Haaretz writes: "The Israeli security apparatus says that work on the wall in the Battir area [control area] has been calculated to cause the least damage possible to the landscape; it says that the wall is of a minimal width and that its route has been changed and moved to the bottom of the slopes in order to minimize damage to the agricultural landscape, even taking into account the security risk, since placement of the wall at the top of a hill allows for better control of an area. The only areas to suffer damage, Israel says, are the bottom terraces, but water will continue to flow to the farmed sections." https : //www.haaretz.com/.premium-j-lem-ecosystem-up-against-the-wall-1.5193375
} 
the deterrent effect of the wall. Our analysis offers empirical evidence to accompany anecdotal (e.g. Collier et al., 2003; Chenoweth and Stephan, 2011) and theoretical (e.g. Dietrich, 2014; Rosendorff and Sandler, 2004) claims that deterrence may lead to resistance via preference change. More generally, however, our analysis adds a new dimension to the economic literature on endogenous preferences and the numerous potential sources of this endogeneity. One strand shows how preferences change as a consequence of evolutionary processes. Direct evolutionary approaches emphasise how agents with fixed strategies or preferences become more or less prevalent in the population as a result of long-term biological equilibria, which reflect the inheritance of successful genetic traits (see (Robson and Samuelson, 2011) for a review) ${ }^{11}$ Alternatively, indirect evolutionary approaches assume agents do not have fixed strategies, and react rationally to their environment, adapting strategies to maximise their 'fitness' (Güth and Yaari, 1992; Huck and Oechssler, 1999). Building on these evolutionary perspectives are several works analysing the cultural transmission of norms and preferences (see Bowles (1998) for a review). This transmission is argued to be influenced by the structure of economic institutions such as markets, and affected by prevailing learning rules such as imitation or conformism. A further line of enquiry focusses on the impact of traumatic life events on specific preference traits, like time and risk preferences. Here, preferences are argued to be endogenous to experiencing events like war violence (e.g Voors et al., 2012; Callen et al. 2014), victimization (Kim and Lee, 2014), natural disasters (Cassar, Healy and Von Kessler, 2017; Cameron and Shah, 2015), or even abrupt economic events (Cohn et al., 2014; Malmendier and Nagel, 2011).

\footnotetext{
${ }^{11}$ The analysis of aggregate equilibrium preference traits, like the social discount rate is often the focus of this literature (see e.g. Robson and Szentes $(2014)$ and Sozou $(2009)$ ).
} 
Our research therefore contributes to the economic literature on endogenous preference change, particularly that part concerned with the impact of abrupt events, shocks, on specific preferences. The chief difference in our work is that the abrupt changes in question are policy driven, and hence closer in spirit to the role of institutional factors in determining preferences discussed in Bowles (1998). Importantly though, in common with the evidence on traumatic life events, reactions to the wall were emotionally-charged, and the emotional response may have some bearing on the direction of preference change. The theoretical connections between emotions, like anger and fear, preference change and behaviour are predominantly studied in social psychology. The most widely cited conceptualization of effects of emotions on decision making, which is highly relevant to the case in hand, is known as the Appraisal Tendency Framework (ATF, originally developed by Lerner and Keltner (2000, 2001) and extended more recently by Cohen-Chen, Crisp and Halperin (2017)). ATF argues that people respond emotionally to specific events depending on how they 'appraise' them. Different emotions are associated with particular dimensions of 'appraisal' and each emotion is related to the emergence of a specific action 'tendency' $\left[\left.{ }^{12}\right|^{13}\right.$ Consequently, informed by the ATF, our questionnaire was

\footnotetext{
${ }^{12}$ These appraisal dimensions include pleasantness, anticipated effort, attentional activity, certainty, perceived obstacles, responsibility attribution (intentionality) and relative strength (controllability). As an example of the 'appraisal'-'action tendency' nexus, anger's core appraisal dimensions are intentionality, a desire for control, and a desire to correct the perceived wrongdoing. When one experiences an event and appraises it as unpleasant or unjust, or one in which responsibility is attributed to another person or group and there is a desire to push back, feelings of anger are more likely to arise as the dominant emotional experience. Anger is a hot state and activates an 'action tendency' towards more risk taking, impulsivity, pushing back and a tendency to see things in extremes (so called 'black and white' thinking). These action tendencies correspond with anger's core appraisal dimensions. In contrast, fear's core appraisal dimensions are uncertainty, low control and low intentionality. Accordingly, these appraisal dimensions generate an action tendency towards aversion to risks, cautious strategies and the desire to create a safer environment.

${ }^{13}$ The effect of anger in the context of initiatives that diminish freedom, like physical barriers and laws, and are perceived unjust, is also elaborated in the earlier theory of Reactance $(\overline{B r e h m}$ and Brehm, 1981; Miron and Brehm, 2006).
} 
designed to elicit the respondents' recollections of the emotions they felt at the moment they found out the wall had been built. Notwithstanding the limitations of a self-reported measure of emotions, Table B.1 in the Supplementary Material shows that subjects exposed to the wall report levels of anger that are significantly higher than subjects without the wall. The feeling of anger and reactance is also apparent from the answers to open-ended qualitative questions. In the results section (Section 5) we discuss how the observed differences in emotions and preferences accord with the ATF. We conclude that the ATF offers a potentially fruitful lens through which to interpret not only our results, but also the previous evidence of the effects of a broader set of significant life events on preferences.

\section{$3 \quad$ Research Design and Data}

In this section we describe the research design tailored to test the hypotheses that the wall has changed individual preferences for risk, ambiguity and time discounting relative to the people not affected ${ }^{14}$ We first describe the sampling frame of our data collection and then present the incentivized decision tasks used to elicit preferences and their implementation, followed by a brief discussion of the accompanying survey data we collected. Additional implementation details are described in the Online Supplementary Material, section B.

\footnotetext{
${ }^{14}$ We analyze the three preferences separately because there is no theoretical reason why risk and ambiguity preferences, and time and ambiguity preferences are correlated Levy et al. (2010). However, time and risk preferences could well be correlated and we will control for this correlation in regressions. Relaxing the assumption of independent equations by estimating a Simultaneous Equation Model does not change the results (see Table D.15 in Supplementary Material, D).
} 


\subsection{Sampling Frame}

There are two noteworthy elements of the sampling frame. First, the wall affects people on either side but with different intensity: people living between the Green Line and the wall face severe mobility restrictions, they are in a 'military zone' cut off from the mainland. These residents live within a state of uncertainty, since the status of these 'enclaves' areas in the face of any peace settlement is dubious. Thus, the practical implications for this group are more severe and hence the exposure to the 'treatment' is more intense. Our sampling frame reflects these two levels of intensity of treatment. We randomly selected villages from three mutually exclusive groups (see Map B.1):

(i) - villages between the Green Line and the wall that are close to the wall and isolated from the West Bank mainland. This group has a higher intensity of treatment since residents are both exposed to and isolated by the wall $\left(T_{h i g h}\right)$;

(ii) - villages that are similarly close to the wall but located in the mainland. This group has a lower intensity of treatment compared to group (i) since residents are exposed to the wall but not isolated by it $\left(T_{\text {low }}\right)$;

(iii) - villages located near the Green Line in areas without wall (not exposed and not isolated). This group serves as control group $(C)$.

Secondly, the sampling frame includes only villages within $5 \mathrm{~km}$ either side of the wall $(5 \mathrm{~km}$ being approximately the maximum distance the wall enters the West Bank 
inland). This is because given the nature of the conflict in this part of the world, it is possible that preferences differ between Palestinians located at the frontier of the West Bank, near the wall, and those far from the frontier. Hence, sampled villages are approximately equally close to Israel.

We randomly selected 5 villages from group (i) in three geographical areas (North, Centre and South of the West Bank, see Map B.1 7 villages (of comparable population size) from group (ii) and 4 control villages from group (iii) located on either side of the proposed route of the segment of wall that is not built yet. Table 1 summarises the design.

Table 1: ReseARCH DESIGN: TREATMENT GROUPS

\begin{tabular}{l|l|l|l}
\hline \hline $\begin{array}{l}\text { Group number/ } \\
\text { Treatment } \begin{array}{c}\text { (high-low } \\
\text { intensity) and Control }\end{array}\end{array}$ & $\begin{array}{l}\text { Isolated from } \\
\text { mainland } \\
\text { (areas between } \\
\text { the wall and the } \\
\text { Green Line) }\end{array}$ & $\begin{array}{l}\text { Exposed to } \\
\text { wall }\end{array}$ & Group name \\
& Yes & Yes & \\
\hline (i, $\left.T_{\text {high }}\right)$ & No & Yes & isolated and exposed \\
$\left(\right.$ ii, $\left.T_{\text {low }}\right)$ & No & No & not expolated, exposed not isolated \\
$($ iii, $C)$ & &
\end{tabular}

\subsection{Experimental Tasks and Survey Data}

To measure preferences for risk, ambiguity and time preferences we implement decision tasks, incentivized with real monetary payoffs. Using tasks with real payoffs presents subjects with clear and equal incentives and allows us to elicit the underlying preferences by observing subject behavior in a controlled setting. We selected tasks and followed protocols that are well-established in the experimental literature

\footnotetext{
${ }^{15}$ We exclude East Jerusalem because the city is under Israeli authority.
} 
in order to elicit individual preferences (L'Haridon and Vieider, 2017).

Task 1: Risk preferences. - We elicit risk preferences (in the gain domain) using an adaptation of the well-established task developed by Holt and Laury (2002) and used in a predominantly Muslim country by Callen et al. (2014). The task is presented in Table 2. Subjects make a series of eleven pair-wise choices between a safe option A, involving a sure payment of NIS 30 (approximately $\$ 8.5$ ), and a relatively risky option $\mathrm{B}$, consisting of a series of gambles over NIS $90(\$ 25.5)$ and 0 with winning probability increasing from zero to 1 . As we go down the list, option $\mathrm{B}$ becomes more attractive and at some point the difference between the expected value of option $\mathrm{A}$ and option $\mathrm{B}$ changes from positive to negative. The point at which a subject switches from preferring option A to option B carries information on his certainty equivalent (that is, the level of risk that makes a subject indifferent between the safe and risky option). We use this information as a (nonparametric) measure of risk aversion $\sqrt{16}$ At the end of the task, one situation is randomly selected and paid out to participants according to their choice. Since any choice may count for payment, subjects are incentivized to respond truthfully to any situation. All subjects are paid.

\footnotetext{
${ }^{16}$ For example, looking at Table 2, we expect a risk-neutral subject to prefer option A in row 3 and to prefer option B in row 4. Subjects who switch from option A to B in earlier rows can be categorized as risk-tolerant and subjects who switch from option A to B in later rows can be categorized as risk-averse.
} 
Table 2: RISK PREFERENCE TASK

\begin{tabular}{|c|c|c|c|}
\hline & OPTION A & $\begin{array}{c}\text { OPTION B } \\
\end{array}$ & $\mathrm{E}(\mathrm{A})-\mathrm{E}(\mathrm{B})$ \\
\hline & Sure payment of 30 NIS & Urn draw: a white ball drawn gives 90 NIS & \\
\hline 0 & $30 \mathrm{NIS}$ & Urn with 0 white balls, 10 black balls & 30 \\
\hline 1 & $30 \mathrm{NIS}$ & Urn with 1 white ball, 9 black balls & 21 \\
\hline 2 & 30 NIS & Urn with 2 white balls, 8 black balls & 12 \\
\hline 3 & $30 \mathrm{NIS}$ & Urn with 3 white balls, 7 black balls & 3 \\
\hline 4 & $30 \mathrm{NIS}$ & Urn with 4 white balls, 6 black balls & -6 \\
\hline 5 & 30 NIS & Urn with 5 white balls, 5 black balls & -15 \\
\hline 6 & 30 NIS & Urn with 6 white balls, 4 black balls & -24 \\
\hline 7 & 30 NIS & Urn with 7 white balls, 3 black balls & -33 \\
\hline 8 & 30 NIS & Urn with 8 white balls, 2 black balls & -42 \\
\hline 9 & 30 NIS & Urn with 9 white balls, 1 black balls & -51 \\
\hline 10 & $30 \mathrm{NIS}$ & Urn with 10 white balls, 0 black balls & -60 \\
\hline \multicolumn{4}{|c|}{$\begin{array}{l}\text { Based on the subjects' choices, we classify subjects as follows: risk-neutral } \\
\text { decision-makers prefer option A over B in rows } 1-3 \text { and option B over A in rows } \\
4-10 ; \text { risk - seeking decision-makers prefer option B over A from any row }<3 \text {; } \\
\text { risk-averse decision-makers prefer option B over A from any row }>4 \text {. Subjects } \\
\text { who prefer option B over A in row } 0 \text { and those who switch more than once } \\
\text { between options are considered inconsistent with rationality and excluded from } \\
\text { the analysis. }\end{array}$} \\
\hline
\end{tabular}

Task 2: Ambiguity preferences. - We elicit ambiguity preferences by adopting a simple task based on the original Ellsberg's two urn thought-experiment and used with non-student subjects in Lauriola and Levin (2001). The task is described in Table 3. Subjects make pair-wise choices between two urns, each containing 10 balls of two colours, one of which carries a prize of NIS 30. In one urn the number of winning balls is known to the subject (this is a risky urn) and this number increases from zero to 10 as the list proceeds. The other urn has a fixed but unknown composition (this is an ambiguous urn). The point at which the subject switches from the 'ambiguous' urn to the 'risky' urn carries information on his risk equivalent, i.e. the known probability of a risky lottery that makes the subject indifferent between the risky and the ambiguous act, and hence his degree of ambiguity aversion. Looking at Table 3, an ambiguity neutral subject is expected to be indifferent between the two urns in row 6; ambiguity averse subjects would switch to the 'risky' urn in earlier rows and ambiguity lovers in later rows. At the end of the task, one situation is selected at random and played for real money according to the subject's choice. 
All subjects are paid. Among tasks eliciting the degree of ambiguity aversion, the task it is easy to understand relative to alternatives found in the literature (see Trautmann and van de Kuilen (2013) for extensive reviews). This was an important consideration given the field nature of the study, and the task proved accessible in the pilot phase 17

Table 3: AmBiguity PREFERENCE TASK

\begin{tabular}{|c|c|c|c|}
\hline & $\begin{array}{c}\text { URN A } \\
\text { Risky Urn }\end{array}$ & $\begin{array}{c}\text { URN B } \\
\text { Ambiguous Urn }\end{array}$ & Classification \\
\hline 1 & Urn with 0 white balls, 10 black balls & $?$ & \\
\hline 2 & Urn with 1 white ball , 9 black balls & $?$ & Ambiguity \\
\hline 3 & Urn with 2 white balls, 8 black balls & $?$ & averse \\
\hline 4 & Urn with 3 white balls, 7 black balls & $?$ & \\
\hline 5 & Urn with 4 white balls, 6 black balls & $?$ & \\
\hline 6 & Urn with 5 white balls, 5 black balls & $?$ & \\
\hline 7 & Urn with 6 white balls, 4 black balls & $?$ & \\
\hline 8 & Urn with 7 white balls, 3 black balls & $?$ & \\
\hline 9 & Urn with 8 white balls, 2 black balls & $?$ & Ambiguity \\
\hline 10 & Urn with 9 white balls, 1 black balls & $?$ & loving \\
\hline 11 & Urn with 10 white balls, 0 black balls & $?$ & \\
\hline \multicolumn{4}{|c|}{$\begin{array}{l}\text { Based on the subjects' choices, we classify subjects as follows: ambiguity-neutral } \\
\text { decision-makers prefer option B over A in rows } 1-5 \text { and prefer option A over B } \\
\text { in rows } 6 \text { - } 11 \text { or prefer option B over A in rows } 1-6 \text { and option A over B in rows } \\
7-11 \text {; ambiguity - loving decision-makers prefer option A over B from any row } \\
\geq 8 ; \text { ambiguity - aver se decision-makers prefer option A over B from any row } \leq \\
5 \text {. Subjects who prefer option A over B in row } 1 \text {, option B over A in row } 11 \text { and } \\
\text { those who switch more than once between options are excluded from the analysis. }\end{array}$} \\
\hline
\end{tabular}

Task 3: Time preferences. - We elicit time preferences with two tasks consisting of two sets of six-pairwise choices between two options: receiving 200 NIS in a month's time (option A) or NIS $200(1+d)^{t}$ at a later time (option B), where $d-$ the discount rate- increases from 0.1 to 0.35 . The tasks are described in Table 4 . Where a subject switches from option A to option B carries interval information on

\footnotetext{
${ }^{17}$ While beliefs about the urn composition may influence the levels of ambiguity preferences, we are comparing differences across treatment groups. There was no reason to think that beliefs about the urn's composition were systematically different across treatment areas. With beliefs orthogonal to treatment, and in an effort to keep participant time at a minimum, we did not elicit beliefs. We did however elicit subjective expectations about the future to test for confounders. These tests support this assertion and are described in Supplementary Material, section D.
} 
his discount rate: the earlier he switches to option B, the more patient he is. Since the time horizon under consideration may matter for discounting, we consider two time horizons and define the delayed time at 2 months in the first and 7 months in the second ${ }^{18}$ Because future money is less certain than instantaneous money, we provide two future options to hold transaction costs of delayed options constant (Harrison, Lau and Williams, 2002) 19

Because of budgetary considerations, in this task we adopt a payoff scheme whereby one single subject per locality is chosen at random to be paid his preferred option from one, randomly selected, choice alternative. Subjects received a certificate, they were told that payments were guaranteed by the University of London, in collaboration with a well-known local research institute, and given contact details of the researchers 20

\footnotetext{
${ }^{18}$ Non-constant, hyperbolic or quasi-hyperbolic discounting, in which people use different discount rates for different time horizons, is a common empirical finding in behavioral economics.

${ }^{19}$ The nature of the task yields a truncated distribution of discount rates bounded at 0.35 . In the course of the field experiments, we received extra funding and were able to extend the list of options between delayed amounts from 6 to 10 pairwise choices in two communities in order to relax the upper bound of the elicited discount rates. We consider various ways to deal empirically with this task's modification. Section 5 presents the more conservative results estimated on the restricted sample of people answering the short (6-)pairwise choice task. Estimation using data on the entire sample, controlling for the type of task answered, makes no difference to the conclusions and results are presented in Table D.3.

${ }^{20}$ The selected payoff scheme retains the incentive compatibility and transparency since most localities are small and respondents are likely to know who is selected for payment and received the money.
} 
Table 4: TIME PREFERENCE TASK

OPTION A: OPTION B:

pays amount below pays amount below

in one month in 2 months

\begin{tabular}{lll}
\hline $\mathbf{1}$ & 200 & 220 \\
$\mathbf{2}$ & 200 & 230 \\
$\mathbf{3}$ & 200 & 240 \\
$\mathbf{4}$ & 200 & 250 \\
$\mathbf{5}$ & 200 & 260 \\
$\mathbf{6}$ & 200 & 270 \\
\hline
\end{tabular}

\begin{tabular}{ccc}
\hline & OPTION A: & OPTION B: \\
\hline & $\begin{array}{c}\text { pays amount below in } \\
\text { one month }\end{array}$ & $\begin{array}{c}\text { pays amount below in } \\
\mathbf{7} \text { months }\end{array}$ \\
\hline $\mathbf{1}$ & 200 & 320 \\
$\mathbf{2}$ & 200 & 380 \\
$\mathbf{3}$ & 200 & 440 \\
$\mathbf{4}$ & 200 & 500 \\
$\mathbf{5}$ & 200 & 560 \\
$\mathbf{6}$ & 200 & 620 \\
\hline
\end{tabular}

Implementation. - We conducted our field experiments in July 2012 and October 2012. The experimental tasks were presented in fixed order as part of a short-questionnaire, covering socio-economic characteristics, personal attitudes and experiences. The average payment per participant was NIS 71, approximately equivalent to the median daily wage in the West Bank (Palestinian Central Bureau of Statistics, 2012) ${ }^{21}$ We administered the survey to 258 participants who were randomly selected and interviewed at their home by female enumerators, in keeping with Palestinian gender norms.

The study aims to test for changes in preferences, without any priming at the time the decision tasks were undertaken. For this reason, the experimental instructions were deliberately anodyne, and made no mention of the wall. In light of the possible sensitivity of questions involving risk in a predominantly Muslim population, in explaining the tasks, we intentionally used wordings similar to Callen et al.

\footnotetext{
${ }^{21}$ Statistics are available on www.pcbs.gov.ps
} 
(2014) who administered a similar risk task in Afghanistan, a much more conservative Muslim society. All interviews started with a consent script.

The percentage of subjects who switched from one option to another more than once in our tasks, or showed other irrational behaviors, is approximately $8 \%$, which is in line with similar field experiments (Callen et al., 2014). We exclude those subjects from the analysis. Table D.11 (in Supplementary Material) shows that this attrition is not systematically related to the treatment status. Further details on implementation are provided in the Supplementary Material (e.g. interviewer training, instruction, incentives).

Survey data. - As part of the interview, participants completed a short questionnaire covering socio-economic information and past experiences, including experiences of conflict. We also undertook a second survey in which we contacted all original participants and invited them to take part in a telephone interview. The survey included questions recollecting the emotions felt at the time of the discovery of the building of the wall (or its planning, for people in locality without wall) ${ }^{22}$ In addition, it included questions related to life expectancy and expectations in various domains of life.

$76 \%$ of the original sample completed the telephone survey. Table B.2 shows that the attrition is not related to exposure to the wall. Importantly, we find no important

\footnotetext{
${ }^{22}$ The data on emotions are recall data relating to the time when the wall was built, not the emotional states during the decision tasks. These data were collected as part of a post-experiment survey and therefore presented no emotional priming for participants. Neither was there any priming related to the wall. Consent forms and experimental instructions made no mention of the wall or the subject's location with respect to it. As further explained in Section 3, the decision tasks were collected in 2012, 10 years after the wall was constructed. For these reasons, the implementation of the decision task is very unlikely to have induced any emotional state such that the observed differences in responses could be interpreted as a temporary, short-lived, phenomenon. Rather, the experiments reveal more fundamental attitudinal traits, and the differences across groups reflect persistent change.
} 
variation in the occurrence of shocks in the period between the experiments and the follow-up survey, increasing confidence that we are not picking up unrepresentative responses influenced by recent experiences.

\section{Causality, Exogeneity and Selection Bias}

In order to identify a causal effect of exposure to the wall on preferences it must be the case that the route taken by the wall is exogenous with respect to individual preferences of Palestinians. Exogeneity in this context has several requirements. First, the wall must not be located so as to spatially separate people with particular preferences (more or less risk averse for instance). A comparison of treatment and control groups would capture pre-existing differences if this were the case. Second, the wall must not induce relocation of people either in anticipation of, or in response to, the wall being built. Thirdly, secular trends in migration must not differ between the treatment and control groups. Differing relocation decisions or migration trends in general could mean that the comparison of treatment and control groups would capture the changing composition of these groups, rather than the object of interest: changing preferences. In the remainder of this section we provide qualitative and quantitative evidence to show that these different dimensions of selection bias are not a threat to exogeneity and the wall can be treated as a natural experiment for our purposes. Quantitative evidence comes from analysis of census data from the entire sampling frame in the period before the wall was built from 1997 to 2002, and from the period after the wall was built from 2002 to $2007 .{ }^{23}$

In relation to the exogeneity of the wall, we do not need to argue that the deci-

\footnotetext{
${ }^{23}$ Details of the analysis are presented in section C of the Supplementary Material.
} 
sion to build the wall is exogenous, we need only argue that the route taken by the wall is exogenous. In this regard, the qualitative evidence strongly suggest that the reasons behind the wall's precise path are unrelated to socio-economic characteristics of the Palestinian population. Official transcripts from the Israeli High Court of Justice state that "operational considerations were the main considerations in selecting the barrier's route" (based on the state's response in Israel's High Court of Justice, case HCJ 7784/02, sec.18). The main reasons for selecting the barrier's route include exogenous considerations, such as topography and Israeli settlement inclusion 24, Discoveries of antiquities caused accidental modifications to the planned route so that excavations could take place on the Israeli side of the wall (such as in Tulkarem district, HCJ 7784/02, sec.30). In other instances, the wall's route was diverted to satisfy political pressure from Israeli citizens ${ }^{25}$ The quantitative evidence from the Census also supports exogeneity. To test for selection bias due to pre-existing differences, we use the individual data from the Population, Housing and Establishment Census 1997, collected prior to the wall construction. Hence, we observe the entire population. The census data provides us with a broad set of socio-economic and background characteristics that are associated with risk, ambi-

\footnotetext{
${ }^{24}$ However, there are settlements either side of the wall and in approximately equal numbers. For example, the Northern enclave has 3 settlements, and there are 2 settlements inland within $5 \mathrm{~km}$ from the wall. In the enclave near Qalqilya there are 7 settlements, and 6 inland within $5 \mathrm{~km}$ from the wall. There is no evidence that the wall was built around more densely populated settlements, in fact close by the initial segments along the northern border there are less populated settlements than the control areas. It must be noted that settlements within the $5 \mathrm{~km}$ radius from the wall are quite old settlements, built between 17-21 years prior to the wall construction. Similarly, the settlements in the control localities were built on average 23 years prior to the wall construction. Individual data on expected violence from settlers does not differ either side of the wall.

${ }^{25}$ For example, in the Qalqilya district, the wall is built in a way that separates small communities, such as Habla and Ras 'Atyia, from the nearest main town of Qalqilya, a few hundred meters north, upon which the smaller communities are dependent for markets and services. The decision driving the wall's route followed a petition from the residents of a nearby Israeli town, Matan, who wanted to maintain access to Road n.55. ("The Battle against the large Qalqilya", Ha'aretz, 27 August 2002).
} 
guity and time preferences (e.g. age, gender, education, marital status, household size and composition). We looked for evidence that would suggest that communities now isolated between the Green Line and the wall, i.e. group (i), were different from communities in group (ii), those now living nearby the wall on the east side of the wall (exposed, not-isolated), and from communities in group (iii), those living in areas without the wall (not-exposed, not-isolated). The last 3 columns of Table C.1 in the Supplementary Material reports the test of mean differences between the treatment groups using the Cohen's $d$ standardized effect-size statistic ${ }^{26}$ The results show that the large majority of the Cohen's $d$ effect-size statistics are well below 0.2 , indicating that the differences between treatment and control areas are of a trivial magnitude. This is evidence that the wall did not follow a route that separated groups with pre-existing differences. Relatedly, other studies on militancy do not support the idea that the starting point of the wall or its route was determined by the presence of militants at the frontier or particular geographical areas (Benmelech, Berrebi and Klor (2012), Figure 1 p.115) nor that, during the wall construction, the length of the wall was correlated with the intensity of suicide attacks towards Israelis (Jaeger and Paserman (2009), Table 8, p.338). Such findings are a strong indication that the path of the wall is essentially exogenous to the outcomes of interest in this study.

Evidence suggests that relocation in anticipation of the wall is unlikely since people could not anticipate the wall's exact location. Reports from B'Tselem, an Israeli Human Rights Organization, suggest that the communication of the wall's

\footnotetext{
${ }^{26}$ Standardized effect size statistics are more informative than a simple t-test in large samples, like the census: the t-test, which depends on the sample size, may show very small difference of no practical relevance as statistically significant. Cohen's statistics of 0.2 (in absolute value) are considered a 'small' effect size indicating minor differences, far from practical significance. Specifically, for groups 1 and 2, the Cohen's $d$ effect-size measures the standardized difference in means: $\left(\mu_{1}-\mu_{2}\right) / \sigma$, where $\sigma$ is the pooled sample standard deviation.
} 
route was unclear and Palestinians could not have been aware of its exact path. B'Tselem reports that, in response to a request of a map of the wall in the early time of construction, a spokesperson of the Ministry of Defence responded that the "publication of the map has not been authorized" and that "information cannot be provided other than what has appeared in the media" (B'Tselem, 2003). The same report provides evidence that the construction of the wall began along paths that were not included in the original decision approved by the Israel's government committee in charge of the plan. ${ }^{27}$ Relocation in response to the wall would also have been beset by institutional hurdles. The residence permit regime in place in isolated areas is such that only residents with a permit can live in isolated areas, hence residents would lose their permit if they moved away. For this reason, mobility is likely to have been very low in these areas, something that is strongly supported by the quantitative evidence.

In order to quantitatively evaluate the claims of low mobility both in anticipation of, and in response to the wall, we return to the Population, Housing and Establishment Census 2007. The 2007 Census has information about the respondent's current locality of residence, how long she has been living there, their previous locality if she moved, and the reason for changing residence. Of the population reporting to have changed place of residence (about $20 \%$ of the population), the median residence duration is 10 years, and only $33 \%$ of migrants moved to their current location between the start of the wall construction and the date of the 2007 Census (i.e. between 2002-2007). The median residence duration of the $67 \%$ who moved before

\footnotetext{
${ }^{27}$ For instance, "In January 2003, the Ministry of Defence began infrastructure work along an additional forty-five kilometer stretch of the barrier, from Sallem eastward to Faqu'a [two towns in the Northern border of the West Bank], that was not included in the Cabinet's [the Ministerial Committee for Security Matter] decision of August 2002 [the decision approving the first section of the route]." (B'Tselem, 2003).
} 
the wall was built is 15 years, so the vast majority of migrants moved to their current location many years before the construction of the wall began. Moreover, of all migrants, only $0.1 \%$ report to have moved because of the wall ${ }^{28}$ According to individual Census responses on migration timing and motivation, it is unlikely that migration was either in anticipation of, or in response to, the building of the wall.

However, it could be that the migration responses to the wall manifest themselves in some other reported motivation. According to the Census 2007 the two main reasons for migration are for marriage ( $25 \%$ of migrants) and to return to the location of origin (e.g. after a period of working elsewhere, 24\%) ${ }^{29}$ However, if the wall induced changes in the timing of these decisions, e.g. earlier marriage and return home, differences would appear in the age of marriage and the age of return to town of origin for those emigrating from the areas affected by the wall for these reasons. We calculate the age of marriage using the Census 2007 data by subtracting duration of residence from current age for the subset who indicate marriage as the reason for migration. We do the same for the returning home decision. Even in this already small subset of population we find no significant differences in age of marriage across the sampling frames for treatment and control groups (see Table C.3 in the Supplementary Material). Relatedly, there are no significant differences in the age composition and population density (see Table C.1.

Turning to the general trends in migration, large migratory flows might also affect the composition of both the area of origin (e.g. by purging areas of origin of risk-

\footnotetext{
${ }^{28} \mathrm{~A}$ small share of the migrant population reports having moved residence because of 'Israeli measures'(3\% of migrants), which may possibly include measures such as the wall. However, an extremely small fraction of these $3 \%$ of people come from 'isolated and exposed' localities $(0.1 \%)$ or 'not-exposed' localities $(0.5 \%)$; hence, this response is unlikely to have anything to do with the wall.

${ }^{29}$ Returning to the town of origin reflects the profound attachment in the Palestinian culture to the family's place of origin and the family's land, and is a strong component of identity.
} 
averse people) and the area of destination (e.g. inflow of a certain type of people). To evaluate this possibility, we coded all the localities of provenance to investigate where people came from and where they moved to in the period after the wall construction (2002-2007) and in the 5 years preceding the wall construction (19972001). The fraction of emigrants relative to the population of their treatment area of origin is at most $1.1 \%$ in the period preceding the wall, and fairly similar across areas (see Table C.2). In the post wall period (2002-2007) the figure is at most $2.8 \%$, and again fairly similar across areas. The fractions of immigrants from each treatment area into other treatment areas are minor, being at most $1.4 \%$ and $5.1 \%$ in the preand post wall periods. These fractions are too small to suggest significant changes in the composition of the population of areas of origin and destination. This conclusion is supported by direct tests of the composition of the populations in terms of age and population density, neither of which differ significantly across the treatment and control populations (See Figure C.1 in the Supplementary Material) 30

The evidence suggests that migration has not been induced by the wall, and is in any event so minor as to have no effect on the composition of the populations in our survey areas. This accords with the fact that, at its core, the PalestinianIsraeli conflict is a conflict over land: attachment to the land is deep-rooted and physical presence over the land is paramount. The general evidence of the rather immobile population is also reflected in our survey data. In our subject sample, the average residence duration among those who reported being born outside their

\footnotetext{
${ }^{30} \mathrm{~A}$ regression of community population growth rates on dummy indicators for communities in group (i) and (ii) yields insignificant coefficients (p-values 0.718 and 0.862 , respectively), suggesting that population growth trends are comparable across treatment and control groups. We compare changes of population density using the 1997 and 2007 Population, Housing and Establishment Census. As expected, population density increases over time, but at comparable rates across areas: the t-statistics on differences in population density between 'isolated and exposed' versus 'not-isolated, exposed' (t-test $=0.70$ ) and versus 'not-exposed, not-isolated' communities (t-test= $0.465)$ do not suggest any significant discrepancy.
} 
current locality is 22 years. There is no difference in average residence duration depending on wall exposure (see Table C.4 in the Supplementary Material). 93.4\% of subjects lived in the sampled villages for at least 10 years, i.e. long before the wall was constructed. We conclude that our sample is not made of recent migrants who would have changed the composition of the treatment groups.

While the evidence we present cannot completely rule out selection on unobservables, it has been argued that the selection effect witnessed when controlling for a large number of observable characteristics can be a good guide to the degree of selection on unobservables (Altonji, Elder and Taber, 2005). Taken together, the qualitative evidence on how the location of the wall was decided, the comparison of pre- and post- wall observable characteristics from the census data, and the evidence against systematic differences in migration patterns, all provide arguments in favour of treating the wall as a natural experiment. Other studies provide evidence that the wall can be considered an exogenous shock and look at criminal behavior within the interior of the West Bank Getmansky, Grossman and Wright (2017).

\section{Results}

The descriptive statistics of our sample of participants by treatment area are shown in Table B.3 in the online Supplementary Material. Socio-economic characteristics across treatment and control groups are balanced 31

First we look at the distributions of preferences (figures in the Supplementary Material). A majority of subjects in our sample (Figure D.1) is risk averse (57.4\%).

\footnotetext{
${ }^{31} \mathrm{~A}$ minor difference is that income of isolated communities appears to be higher than notisolated communities (at the 10\% level). In our regressions we control for income, as well as additional control variables.
} 
The correlation between risk aversion, measured by the switching point in decision task 1, and individuals' characteristics is in line with typical results found in the literature, e.g. Dohmen et al. (2011). 32

In terms of ambiguity preferences, we find significant ambiguity aversion in our sample (74\% of sample, Figure D.2), with a notable degree of heterogeneity. Again, these results are in line with those elsewhere in the literature Chakravarty and Roy, 2009; Ahn et al. 2014). The mean risk equivalent, i.e. the known probability of a risky lottery that is considered equivalent to the ambiguous option, for the whole sample is 0.4, significantly lower than 0.5, even-odds, expected for an ambiguity neutral agent $(\mathrm{p}<0.001)$.

In terms of time preferences, the mean discount rate for the short horizon experiment (payments in month 1 or 2 ) was approximately $21 \%$, in line with the previous literature ${ }^{33}$ For the long-horizon experiment (payments in month 1 or 7 ) the mean discount rate is substantially lower at $13 \%$. This statistically significant difference is suggestive of discount rates that vary with the time-horizon.

Our primary interest is to analyze if individual preferences are affected by the wall, while distinguishing between two levels of treatment intensity: one treatment is being exposed to the wall, as for treatment group (ii); a more intense treatment is being exposed to the wall and isolated by it, as for treatment group (i). In

\footnotetext{
${ }^{32}$ Risk aversion is positively associated with female gender $\left(0.123^{* *}\right)$, age $\left(0.125^{* *}\right)$ and negatively with education (-0.090) and income (-0.07) although not significantly. We also find the expected correlations between risk aversion and smoking $\left(-0.095^{*}\right)$, self-employment $(-0.012)$ and behaviors in a hypothetical scenario involving risk, such as accepting an offer to go to Jerusalem without holding a permit $\left(-0.12^{* *}\right)$. We find significant correlations with two self-assessment questions of risk preferences, i.e. the willingness to take risk in general $\left(-0.147^{* *}\right)$ and in financial matters $\left(-0.194^{* * *}\right)$, in line with Dohmen et al. (2011).

${ }^{33}$ Given the way in which the payments were organized, expected rewards are (inversely) related to the size of the group interviewed in each village. Including group size as an explanatory variable in the regression specifications for time preferences provides a mean of checking for responses associated with payments that were perceived to be small. The results are unaffected by including group size.
} 
Table 5 we show the regressions of categorical measures of risk, ambiguity and time preferences derived from the decision tasks on dummy indicators for treatment communities in group (i) and (ii). The control group (iii) is the base category. If the wall has an impact on preferences we should observe significant coefficients on the dummy variables for group (i) and (ii). We expect group (i), which receives a more intense treatment, to have larger differences from control communities than group (ii). In our regressions, we include gender, age, education and income as control variables. Standard errors are bootstrapped (clustered bootstrapping at the community level). For robustness a series of alternative inferential methods (e.g. randomization inference and wild-bootstrap standard errors) are presented in Table D.14 in Supplementary Material. We present additional regressions using villagelevel control variables in tables D.1 D.2.

Our chief result is that exposure to the wall affects preferences. In the domain of risk preferences, column (1) of Table 5 shows the estimates from an OLS regression on 'treatment' dummies and controls. The results show that compared to people living in areas without the wall, people exposed to the wall have become more risk tolerant. Furthermore, the extent of this increase in risk tolerance increases with the intensity of exposure: communities exposed and isolated by the wall become more risk tolerant than the other groups. An ordered probit specification leads to qualitatively the same results.

To test the robustness of these results, we deploy a host of additional robustness checks. The results remain robust to the inclusion of control variables, including gender, age and its square, income and educational attainment. We also check the robustness of the results to the inclusion of wealth (proxied by the availability of savings), having lost private land due to the wall construction, and village level 
characteristics. These results are reported in Table D.1 in Supplementary Material. 34 We also check whether the results are being driven by changes in subjective expectations about the future, rather than changes in the preferences themselves. Our intention is to allay concerns about the results being driven by subjective negative economic outlooks (see Table D.13 in Supplementary Material). Again, the evidence speaks against this alternative explanation.

We also find that the wall has affected preferences over ambiguity. The OLS estimated coefficients are presented in column (2) of Table 5. Compared to people without the wall, people who are exposed to the wall are generally more ambiguity averse and this effect is larger if they are also isolated by the wall. In the case of ambiguity preferences the regression estimates show that there is no gender or income effect on ambiguity preferences, which is in accordance with results in the literature (Sutter et al., 2013). Throughout the specifications, our results suggest that ambiguity tolerance increases with age and with education, similarly to previous evidence (Baillon, Koellinger and Treffers, 2016). The differences in ambiguity preferences of treatment groups compared to the control group remain robust when adding availability of savings, having lost land, and village level characteristics (Table D.2 in Supplementary Material).

At first glance, an increase in risk tolerance conjoint with an increase in ambiguity aversion may seem counterintuitive. Yet, such a combination of changes is not necessarily out of the ordinary. First, risk and ambiguity are theoretically different domains: risk describes situations with well-defined, known probabilities; ambiguity refers to situations in which probabilities are unknown or vague. Pref-

\footnotetext{
${ }^{34}$ Throughout the results, we find a non-linear effect of age. Although not statistically significant in multivariate specifications, simple regressions of risk preferences on gender suggest that females are more risk averse than males, a result consonant with previous literature.
} 
erences over each domain can differ. For instance, one may think of situations in which, faced with unknown likelihoods of decision consequences, a person is sensitive to the lack of information and acts cautiously or even pessimistically - placing the lowest likelihood on good outcomes, that is, behaving in an ambiguity averse manner. However, she is willing to take on a risky decision if the likelihoods are clear (unambiguous). More generally, the desire to avoid bad outcomes can trigger risky actions ${ }^{35}$ Furthermore, the shift towards more risk tolerance and ambiguity aversion that we observe in our study does not leave people with an unusual combination of preferences, either with regard to the control group 36 or more generally what is found in the literature (Borghans et al., 2009).

For time preferences, we follow the literature and estimate a (discrete time) proportional hazard model $[37$ A negative coefficient is an indication of more impatient preferences (i.e. they are less likely to switch to the later-in-time option in the task). Column (3) and Column (4) of Table 5 show the estimated model for the short-time horizon and the long-time horizon, respectively. While there are no differences in patience across groups in the short-horizon, exposure to the wall significantly affects patience in the long-time horizon. The results show that people belonging to the communities exposed to the wall but not-isolated are significantly more impatient than people without the wall: their tendency to prefer the later

\footnotetext{
${ }^{35}$ Consider someone receiving an uncertain diagnosis of a rare, not well known, cancer. There is uncertainty about the chances of survival and the individual response to treatments. A patient may well care most about the very bad outcome: death, and make decisions on the basis that the probability of this outcome is high (a 'maxmin' preference, to use ambiguity theory terminology). She is ambiguity averse. She may then do anything to avoid the worst outcome and accept risky medical treatments or experimental trials. That is, she may take on a risky action.

${ }^{36}$ Results are available from the authors.

${ }^{37}$ Time preferences are inferred by the transition to the later-in-time option of the task. The later a subject makes the transition to choosing the future option, the more impatient she is. Hazard models are common because they directly model the transition probability. An impatient subject has a lower probability of transition to the later-in-time option than a patient subject.
} 
option decreases by $25 \%(=\exp (\beta)-1)$ over the baseline tendency. The effect is stronger for people exposed to the wall and isolated by it: their tendency to prefer the later option decreases by $38 \% .38$ The combination of these results indicate that on average those exposed to the wall discount longer time horizons at higher rates than the unexposed.

More generally, the results accord with the findings in the literature about females being more patient on average, older people being more impatient, and better educated people being more patient. As the future may be risky (and risk preferences are affected by the wall), we control for risk aversion as elicited in the risk preference task. We find that more risk averse people tend to discount the future more heavily, which is consistent with previous research (Andersen et al., 2008).

The impacts on preferences are not driven by past experiences of violence (see Tables D.4, D.5, D.6 in Supplementary Material). As an additional sensitivity test for omitted variables, we compute the statistics suggested by Altonji, Elder and Taber (2005) and Oster (2019). These tests indicate the degree of selection on unobservables relative to observables which would be necessary to explain away the impact of the wall. We present these statistics in Table D.16 in Supplementary Material. In most cases, the ratios suggested by these methods are negative. Negative ratios arise when the observable controls are on average negatively correlated with the treatment and positively with the outcome (or vice-versa). This implies that our estimates are, if anything, attenuated towards zero by unobservable characteristics and can be interpreted as lower bounds of the true impact. We discuss and present additional robustness checks in Section D of Supplementary Material.

\footnotetext{
${ }^{38}$ These results include all subjects answering the same task. If we include those subjects answering the extended version of the time preference task and use an indicator variable to control for the type of task, the results are unchanged (see Table D.3 in Supplementary Material).
} 
Overall, these results suggest that exposure to the wall has affected people's preferences: compared to areas without wall, people in communities exposed to the wall are more risk tolerant, ambiguity averse and more impatient in the long term. These differences are stronger for people exposed to the wall and isolated by it. Given this change in preferences the deterrent effect of the wall may be less than expected ${ }^{39}$ These results are in line with the effects expected by the ATF: a common emotional response to the wall was anger, which is heightened among people exposed to the wall (see Table B.1). According to the ATF, anger's core appraisal dimensions activate an 'action tendency' towards risk seeking, impulsivity and 'black and white' thinking 40

We have no direct evidence of whether the changes in preferences observed in our subjects translate into changes in violent behaviour. However, we geo-referenced data from PCPSR quarterly opinion poll undertaken in two years close to the time of our field experiments (years 2011 and 2012, N=1,011). These data show that within our sampling frame support for armed resistance is significantly higher in those areas close to the wall. Indeed, the differences are striking: support for armed resistance is at $21 \%$ in areas without wall; it goes up to $33 \%$ in areas close to the wall. Of course, increased support for violence by an individual is not sufficient to induce that individual to engage in violent actions. The variety of situational factors that lead to action make the correlation between behaviour and attitude necessarily less than one (Khalil, Horgan and Zeuthen, 2019). Yet, at the individual level, it

\footnotetext{
${ }^{39}$ Based on these findings, the potential identification concern that the wall had been purposefully built to separate risk taking Palestinians from Israel appears implausible.

${ }^{40} \mathrm{~A}$ separate matter is the process through which preference change arises: was it an immediate preference change that persisted or a gradual process which accumulated over time? We are unable to distinguish empirically between these two processes with our data. However, ATF and the evidence on recalled emotions would suggest that an immediate yet persistent process is more likely.
} 
has been argued that attitudes supporting aggression are a good predictor of violent actions (see e.g., Kernsmith (2005) in the context of domestic violence; CopelandLinder et al. (2012) in the context of aggression). More generally, it has also been argued that support for violence in the wider community can help motivate the emergence of violence and resistance (McCauley and Moskalenko, 2017, p. 206)), which would make opinions and behaviour likely to be positively correlated in the aggregate. The direct impact on violent behaviour remains an important avenue for future research. 
Table 5: PREFERENCES AND EXPOSURE TO THE WALL

\begin{tabular}{|c|c|c|c|c|}
\hline & (1) & (2) & $(3)$ & (4) \\
\hline & Risk aversion & Ambiguity aversion & $\begin{array}{c}\text { Time preferences } \\
\text { (patience) } \\
\text { short horizon } \\
\text { (HAZARD) }\end{array}$ & $\begin{array}{c}\text { Time preferences } \\
\text { (patience) } \\
\text { long horizon } \\
\text { (HAZARD) }\end{array}$ \\
\hline (ii) not-isolated, exposed & $\begin{array}{c}-0.263^{* *} \\
(0.110)\end{array}$ & $\begin{array}{l}0.197^{*} \\
(0.115)\end{array}$ & $\begin{array}{l}-0.040 \\
(0.131)\end{array}$ & $\begin{array}{c}-0.280^{* *} \\
(0.114)\end{array}$ \\
\hline (i) isolated, exposed & $\begin{array}{c}-0.458^{* * *} \\
(0.131)\end{array}$ & $\begin{array}{c}0.285^{* * *} \\
(0.103)\end{array}$ & $\begin{array}{c}-0.009 \\
(0.139)\end{array}$ & $\begin{array}{c}-0.479 * * * \\
(0.125)\end{array}$ \\
\hline female & $\begin{array}{c}0.119 \\
(0.112)\end{array}$ & $\begin{array}{l}-0.100 \\
(0.072)\end{array}$ & $\begin{array}{c}0.641^{* * * *} \\
(0.104)\end{array}$ & $\begin{array}{c}0.309^{* * *} \\
(0.095)\end{array}$ \\
\hline age (in years) & $\begin{array}{c}0.096^{* *} \\
(0.029)\end{array}$ & $\begin{array}{l}-0.032 \\
(0.020)\end{array}$ & $\begin{array}{c}0.015 \\
(0.027)\end{array}$ & $\begin{array}{l}0.042^{*} \\
(0.024)\end{array}$ \\
\hline age (squared) & $\begin{array}{c}-0.001^{* *} \\
(0.000)\end{array}$ & $\begin{array}{c}0.000 \\
(0.000)\end{array}$ & $\begin{array}{l}-0.000 \\
(0.000)\end{array}$ & $\begin{array}{c}-0.000^{*} \\
(0.000)\end{array}$ \\
\hline income & $\begin{array}{l}-0.017 \\
(0.025)\end{array}$ & $\begin{array}{l}-0.014 \\
(0.017)\end{array}$ & $\begin{array}{c}0.035 \\
(0.022)\end{array}$ & $\begin{array}{l}-0.009 \\
(0.020)\end{array}$ \\
\hline education & $\begin{array}{c}0.053 \\
(0.046)\end{array}$ & $\begin{array}{c}-0.102^{* *} \\
(0.034)\end{array}$ & $\begin{array}{c}0.184^{* * *} \\
(0.041)\end{array}$ & $\begin{array}{c}0.144^{* * *} \\
(0.035)\end{array}$ \\
\hline risk aversion & & & $\begin{array}{c}-0.229^{* * *} \\
(0.054)\end{array}$ & $\begin{array}{c}-0.402^{* * *} \\
(0.048)\end{array}$ \\
\hline constant & $\begin{array}{c}-1.567^{* *} \\
(0.519)\end{array}$ & $\begin{array}{c}1.458^{* * *} \\
(0.339)\end{array}$ & & \\
\hline period dummies (baseline hazard) & & & Yes & Yes \\
\hline Observations & 237 & 245 & 1272 & 1278 \\
\hline$\sharp$ Subjects & 237 & 245 & 212 & 213 \\
\hline R-squared /L* & 0.109 & 0.104 & $-732^{*}$ & $-715^{*}$ \\
\hline
\end{tabular}

The dependent variable in column (1) is an (ordinal) categorical variable increasing in risk-aversion; in column (2) is a categorical variable increasing in ambiguity aversion; in columns (3)-(4) is a binary indicator coded 1 from the period (choice situation) in which a subject switches to the delayed option in short horizon task and long horizon task, respectively (the model is estimated using a proportional hazard model, using a complementary log-log function). Variable '(ii) Not-isolated, exposed' is a dummy variable $=1$ if the subject lives in a community in group (ii), i.e. on the east side of the wall ('not-isolated but exposed communities'); variable '(i) isolated, exposed' is a dummy variable $=1$ if the subject lives in a community in group (i), that is a community between the Green Line and the wall; the reference category is group (iii), 'not-isolated and not-exposed'. Variable 'age' is subject's age measured in years (and its squared); variable 'female' is a dummy variable $=1$ if the subject is female; 'income' is a categorical variable indicating income level categories (0-1000, 1000-1500, 1500-2000, etc.); 'education' is a categorical variable indicating educational attainment. Clustered bootstrapped standard errors in parentheses. Ordered probit specifications for models in columns (1) and (2) yield qualitatively identical results. Using OLS specifications with the switching points as dependent variable also yield qualitatively similar results. The main results are robust to inclusion of village level variables, such as altitude, population density and the proportion of households owning a PC (a proxy for village income). Observations include rational subjects in each task.

\section{Discussion and Conclusion}

The principle of deterrence is advocated by many rational agent models and applied to counter-violence initiatives. The main assumption in these models is that preferences remain unchanged, and the logic of deterrence follows from this assumption on 
preferences: deterrence policies will decrease armed actions once and for all. Contrary to this, we show that preferences of Palestinians affected by a major deterrence policy, the wall between the West Bank and Israel, have changed in response. These findings are in line with the theoretical insights from social psychology which argue that deterrent policies generating anger and reactance, in turn change the preferences of affected people in ways which are less conducive to appeasement. Our findings show that Palestinian individuals directly exposed to the wall are more risk tolerant, sensitive to uncertainty and, for long time horizons, more impatient than people living in areas without the wall. These effects are stronger for people living in areas cut off from the West Bank mainland and thus more severely affected by the wall. Our analysis also reveals more support for armed action from the same population at the aggregate level.

At a theoretical level, the paper makes two contributions. First, our findings reveal a new behavioural explanation as to why certain deterrent policies may not work as expected and possibly create backlash. The reason rests on the possibility that the parameters that govern people' valuations of net gains from committing political actions change after the policy. The different valuations in turn cause changes in political behaviours beyond (and possibly in opposition to) what is expected from the deterrent. Specifically, if one conceives acts of aggression as risky, higher risk tolerance and impatience increase the perceived gain from aggression, because individuals place less weight upon the riskiness of actions and possible future costs 41

\footnotetext{
${ }^{41}$ Thinking of acts of aggression as risky prospects is intuitive and accords to existing theoretical models of aggression. Yet, at least theoretically, acts of aggression can also be perceived as ambiguous prospects. However, the long lasting nature of the Israeli-Palestinian conflict makes the range and frequency of the consequences of violent actions known, familiar and predictable, making it more likely that they will be perceived as risky rather than ambiguous. Dacey (1998) discusses known punitive measures applied throughout the years; at the aggregate level, Durante and Zhuravskaya (2018) and Jaeger and Paserman (2008) illustrate the predictability of Israeli counter-violence response using time-series data.
} 
Increased ambiguity aversion is also associated with difficulties building trusting relationships (e.g. Li, Turmunkh and Wakker, 2019). Absence of trust may prompt both retaliatory and pre-emptive violent acts and, in extreme cases, can "plunge societies in vicious cycles of recurrent conflict" (Rohner, Thoenig and Zilibotti, 2013, p.1114). We do not have evidence on trust per se, but the diminution of trust is one mechanism through which increased ambiguity aversion may encourage more violence and thus undermine deterrence in this context. Ambiguity aversion may also dissuade engagement in peace negotiations, whose outcomes have inherently unknown probabilities, by increasing support for known states of the world, like the status quo 42

Secondly, we extend previous research on the effectiveness of deterrent policies by combining theoretical insights from social psychology with a rational choice framework, and then empirically testing these insights in the context of a real deterrent initiative. Our results point to the importance of considering the emotional responses to explain the direction in which these policies may be changing the calculations of net gains from action. Our findings support an association between anger/provocation and changes towards more risk tolerance, aversion to uncertainty and myopia. These findings speak in favour of theoretical models with endogenous preference formation, as opposed to fixed and unalterable preferences typical of more traditional economic models. More generally, the existing evidence on the impact

\footnotetext{
${ }^{42}$ It is possible that violent acts are perpetrated by a small minority or specific groups. An important question we are unable to test is whether a minority responsible for violence experience the same changes that we report for the population on average. If the preferences of this minority are impacted differently than the average effect on the majority, the treatment effect would be heterogeneous and violence could arise for different reasons than those described in the paper. Comparing the treatment and control groups shows that the change in the joint distribution of preferences, for example risk and ambiguity preferences, looks more like a location-shift towards risk tolerance and ambiguity aversion, suggesting there is limited heterogeneity in the treatment effect. In general, however, within-subject change in preferences and its heterogeneity is of great interest for future work.
} 
of acute life events on preferences can be viewed through the lens of the Appraisal Tendency Framework, which provides a possible explanation as to why some studies show different, sometimes opposing, effects of shocks on preferences. For instance, studies on natural disasters and financial downturns find increased risk aversion in the aftermath of the shock (Cassar, Healy and Von Kessler, 2017; Cameron and Shah, 2015, Malmendier and Nagel, 2011; Cohn et al., 2014), while studies on the direct exposure to violence from an enemy (Voors et al., 2012) suggest less risk aversion. These events are likely to differ in terms of cognitive appraisal (e.g. their pleasantness, controllability and presence or absence of intentionality) and those differences shape the elicitation of distinctive emotions. These emotions have associated action tendencies which drive the behavioural responses to the event. Events that elicit different emotions will yield different impacts on underlying preferences.

At a practical level, our findings have notable implications for the dynamics of the long-standing conflict in the region. The results highlight that the wall is a potential obstacle to peace. Risky acts of resistance may become more desirable for people who have become more risk tolerant and sensitive to uncertainty. Similarly, attitudes towards proposed (or to be proposed) peace treaties depend on the immediate costs and later benefits of the proposal. Greater impatience may reduce the range of proposals that will be acceptable to individuals when they evaluate the costs and benefits of their actions.

Looking around the world there are many examples of harsh or repressive policies, including those where physical barriers have been erected to impose control, seal up borders and restrict movements (e.g., India and Bangladesh, Belfast, Morocco and Western Sahara, USA and Mexico, Greece and Turkey, Cyprus). Our results speak to many such cases, and show that there may be unintended and counter-productive 
consequences of these measures, due to preference change among affected parties. 


\section{References}

Ahn, David, Syngjoo Choi, Douglas Gale and Shachar Kariv. 2014. "Estimating ambiguity aversion in a portfolio choice experiment." Quantitative Economics $5(2): 195-223$.

Altonji, Joseph G, Todd E Elder and Christopher R Taber. 2005. "Selection on Observed and Unobserved Variables: Assessing the Effectiveness of Catholic Schools." Journal of Political Economy 113(1):151.

Andersen, Steffen, Glenn W. Harrison, Morten I. Lau and E. Elisabet Rutstrom. 2008. "Eliciting Risk and Time Preferences." Econometrica 76(3):583-618.

Baillon, Aurelien, Philipp Koellinger and Theresa Treffers. 2016. "Sadder but wiser: the Effects of Affective States and Weather on Ambiguity Attitudes." Journal of Economic Psychology 53:67-82.

Benmelech, Efraim, Claude Berrebi and Esteban F Klor. 2012. "Economic conditions and the quality of suicide terrorism." The Journal of Politics 74(01):113-128.

Borghans, Lex, James J Heckman, Bart HH Golsteyn and Huub Meijers. 2009. "Gender differences in risk aversion and ambiguity aversion." Journal of the European Economic Association 7(2-3):649-658.

Bowles, Samuel. 1998. "Endogenous preferences: The cultural consequences of markets and other economic institutions." Journal of Economic Literature pp. 75-111.

Brehm, S. and Jack Brehm. 1981. Psychological Reactance: A Theory of Freedom and Control. New York: Academic Press.

B'Tselem. 2003. Behind The Barrier - Human Rights Violations As a Result of Israel's Separation Barrier. Report The Israeli Information Center for Human Rights in the Occupied Territories. https://www.btselem.org/download/ 200304_behind_the_barrier_eng.pdf.

B'Tselem. 2012. Arrested development - The long term impact of Israel's Separation barrier in the West Bank. Report The Israeli Information Center for Human Rights in the Occupied Territories. http://www.btselem.org/download/ 201210_arrested_development_eng.pdf. 
Callen, Michael, Mohammad Isaqzadeh, James D. Long and Charles Sprenger. 2014. "Violence and Risk Preference: Experimental Evidence from Afghanistan." The American Economic Review 104(1):123-148.

Cameron, Lisa and Manisha Shah. 2015. "Risk-taking behavior in the wake of natural disasters." Journal of Human Resources 50(2):484-515.

Canetti, Daphna, Brian J Hall, Carmit Rapaport and Carly Wayne. 2013. "Exposure to political violence and political extremism." European Psychologist .

Canetti-Nisim, Daphna, Eran Halperin, Keren Sharvit and Stevan E Hobfoll. 2009. "A new stress-based model of political extremism: Personal exposure to terrorism, psychological distress, and exclusionist political attitudes." Journal of Conflict Resolution 53(3):363-389.

Cassar, Alessandra, Andrew Healy and Carl Von Kessler. 2017. "Trust, risk, and time preferences after a natural disaster: experimental evidence from Thailand." World Development 94:90-105.

Chakravarty, Sujoy and Jaideep Roy. 2009. "Recursive expected utility and the separation of attitudes towards risk and ambiguity: an experimental study." Theory and Decision 66:199-228.

Chenoweth, Erica and Maria J Stephan. 2011. Why civil resistance works: The strategic logic of nonviolent conflict. Columbia University Press.

Cohen-Chen, Richard J., Richard J. Crisp and Eran Halperin. 2017. "A New Appraisal-Based Framework Underlying Hope in Conflict Resolution." Emotion Review 9(3):208-214.

Cohen, Jacob. 2013. Statistical power analysis for the behavioral sciences. Routledge.

Cohen, M., J. M. Tallon and J. C. Vergnaud. 2011. "An experimental investigation of imprecision attitude and its relation with risk attitude and impatience." Theory and Decision 71(1):81-109.

Cohn, Alain, Jan Engelmann, Ernst Fehr and Michel Maréchal. 2014. "Evidence for countercyclical risk aversion: an experiment with financial professionals." American Economic Review forthcoming. 
Collier, Paul et al. 2003. Breaking the conflict trap: Civil war and development policy. World Bank Publications.

Copeland-Linder, Nikeea, Sara B Johnson, Denise L Haynie, Shang-en Chung and Tina L Cheng. 2012. "Retaliatory attitudes and violent behaviors among assaultinjured youth." Journal of Adolescent Health 50(3):215-220.

Dacey, Raymond. 1998. "Risk attitude, punishment, and the Intifada." Conflict Management and Peace Science 16(1):77-88.

De Mesquita, Ethan Bueno. 2005. "The quality of terror." American Journal of Political Science 49(3):515-530.

Dietrich, Franz. 2014. "Anti-terrorism policies and the risk of provoking." Journal of Theoretical Politics 26(3):405-441.

Dohmen, T., A. Falk, D. Huffman, U. Sunde, J. Schupp and G. G. Wagner. 2011. "Individual Risk Attitudes: Measurement, Determinants and Behavioral Consequences." Journal of the European Economic Association 9(3):522-550.

Dunning, Thad. 2012. Natural experiments in the social sciences: A design-based approach. Cambridge University Press.

Durante, Ruben and Ekaterina Zhuravskaya. 2018. "Attack when the world is not watching? US news and the Israeli-Palestinian conflict." Journal of Political Economy 126(3):1085-1133.

Getmansky, Anna, Guy Grossman and Austin L. Wright. 2017. Border fortification and the economics of crime. Technical report. https: //www.researchgate.net/publication/304251182_Border_Fortification_ and_the_Economics_of_Crime.

Güth, W. and M. Yaari. 1992. An Evolutionary Approach to Explain Reciprocal Behavior in a Simple Strategic Game. In Explaining Process and Change? Approaches to Evolutionary Economics, ed. U. Witt. Ann Arbor pp. 23-34.

Harrison, Glenn W., Morten I. Lau and Melonie B. Williams. 2002. "Estimating Individual Discount Rates in Denmark: A Field Experiment." American Economic Review 92(5):1606-1617. 
Holt, Charles A. and Susan K. Laury. 2002. "Risk Aversion and Incentive Effects." American Economic Review 92(5):1644-1655.

Huck, Steffen and Jörg Oechssler. 1999. "The indirect evolutionary approach to explaining fair allocations." Games and Economic Behavior 28(1):13-24.

Huettel, Scott A., C. Jill Stowe, Evan M. Gordon, Brent T. Warner and Michael L. Platt. 2006. "Neural Signatures of Economic Preferences for Risk and Ambiguity." Neuron 49(5):765 - 775 .

Jaeger, David A and M Daniele Paserman. 2008. "The cycle of violence? An empirical analysis of fatalities in the Palestinian-Israeli conflict." American Economic Review 98(4):1591-1604.

Jaeger, David A and M Daniele Paserman. 2009. "The shape of things to come? On the dynamics of suicide attacks and targeted killings." Quarterly Journal of Political Science 4(4):315-342.

Kalyvas, Stathis N. 2004. "The paradox of terrorism in civil war." The Journal of Ethics 8(1):97-138.

Kernsmith, Poco. 2005. "Treating perpetrators of domestic violence: Gender differences in the applicability of the theory of planned behavior." Sex Roles 52(1112):757-770.

Khalil, James, John Horgan and Martine Zeuthen. 2019. "The Attitudes-Behaviors Corrective (ABC) Model of Violent Extremism." Terrorism and Political Violence pp. 1-26.

Kim, Young-Il and Jungmin Lee. 2014. The long-run impact of traumatic experience on risk aversion. Technical report.

Lauriola, Marco and Irwin P. Levin. 2001. "Relating Individual Differences in Attitude toward Ambiguity to Risky Choices." Journal of Behavioral Decision Making 14(2):107-122.

Lerner, Jennifer S and Dacher Keltner. 2000. "Beyond valence: Toward a model of emotion-specific influences on judgement and choice." Cognition 83 Emotion 14(4):473-493. 
Lerner, Jennifer S. and Dacher Keltner. 2001. "Fear, anger, and risk." Journal of Personality and Social Psychology 81(1):146-159.

Levy, I., Snell J., A. J. Nelson, A. Rustichini and P. W. Glimcher. 2010. "Neural representation of subjective value under risk and ambiguity." Journal of Neurophysiology 103(2):1036-1047.

L'Haridon, Olivier and Ferdinand Vieider. 2017. "All Over the Map A Worldwide Comparison of Risk Preferences." Journal of Quantitative Economics .

Li, Chen, Uyangaand Turmunkh and Peter P. Wakker. 2019. "Trust as a decision under ambiguity." Experimental Economics 22:51?75.

Malmendier, Ulrike and Stefan Nagel. 2011. "Depression Babies: Do Macroeconomic Experiences Affect Risk Taking?" The Quarterly Journal of Economics 126(1):373-416.

McCauley, Clark and Sophia Moskalenko. 2017. "Understanding political radicalization: The two-pyramids model." American Psychologist 72(3):205.

Miron, Anca M and Jack W Brehm. 2006. "Reactance theory-40 years later." Zeitschrift für Sozialpsychologie 37(1):9-18.

Moya, Andrés. 2018. "Violence, Psychological Trauma, and Risk Attitudes: Evidence from Victims of Violence in Colombia." Journal of Development Economics 131:15-27.

OCHA. 2009a. Five years after the International Court of Justice advisory opinion. Technical report United Nations - Office for the Coordination of Humanitarian Affairs Jerusalem: . https://unispal.un.org/pdfs/BarrierRpt_0709.pdf.

OCHA. 2009b. Shrinking space: urban concentration and rural fragmentation in the Bethlehem governorate. Technical report United Nations - Office for the Coordination of Humanitarian Affairs Jerusalem: . https://www.ochaopt.org/content/ shrinking-space-urban-contraction-and-rural-fragmentation [hyphen] bethlehem-governorate-may-2009

OCHA. 2011. Barrier update: the impact of the Barrier in the Jerusalem area. Technical report United Nations - Office for the Coordination of 
Humanitarian Affairs Jerusalem: . https://www.ochaopt.org/content/ impact-barrier-jerusalem-area.

Oster, Emily. 2019. "Unobservable selection and coefficient stability: Theory and evidence." Journal of Business \& Economic Statistics 37(2):187-204.

Robson, Arthur J. and Balázs Szentes. 2014. "A Biological Theory of Social Discounting." American Economic Review 104(11):3481-3497.

Robson, Arthur J. and Larry Samuelson. 2011. The Evolutionary Foundations of Preferences. In Handbook of Social Economics, ed. Jess Benhabib, Alberto Bisin and Matthew O. Jackson. Vol. 1 North-Holland chapter 7, pp. 221-310.

Rohner, D., M. Thoenig and F. Zilibotti. 2013. "War Signals: A Theory of Trade, Trust and Conflict." Review of Economic Studies 80(3):1114-1147.

Rosendorff, B Peter and Todd Sandler. 2004. "Too much of a good thing? The proactive response dilemma." Journal of Conflict Resolution 48(5):657-671.

Sawilowsky, Shlomo S. 2009. "New Effect Size Rules of Thumb." Journal of Modern Applied Statistical Methods 8(2):597-599.

Sozou, Peter. 2009. "Individual and social discounting in a viscous population." Proc. R. Soc. Lond. B 276(1669):2955-2962.

Sutter, Matthias, Martin G Kocher, Daniela Glatzle-Rutzler and Stefan T Trautmann. 2013. "Impatience and uncertainty: Experimental decisions predict adolescents' field behavior." The American Economic Review 103(1):510-531.

Trautmann, Stefan T. and G. van de Kuilen. 2013. Blackwell Handbook of Judgment and Decision Making. Blackwell chapter Ambiguity Attitudes, p. forthcoming. http://www.bbk.ac.uk/ems/research/Seminar_info/ spring-2014-15-1/trautmannvdKuilen_AmbRev_april2014FINAL.pdf.

Vieider, Ferdinand M. 2018. "Violence and risk preference: experimental evidence from Afghanistan: comment." American economic review 108(8):2366-82.

Voors, M., E. Nillesen, P. Verwimp, E. Bulte, R. Lensink and D. van Soest. 2012. "Violent Conflict and Behavior: A Field Experiment in Burundi." American Economic Review 102(2):941-964. 
Walter, Barbara F. 2004. "Does conflict beget conflict? Explaining recurring civil war." Journal of Peace Research 41(3):371-388.

World Bank, The. 2008. The economic effects of restricted access to land in the West Bank. Technical report The World Bank, Washington DC. http://documents.worldbank.org/curated/en/654801468176641469/ pdf/473230WPOGZORe101PUBLIC10Box334128B.pdf.

Zeitzoff, Thomas. 2014. "Anger, Exposure to Violence, and Intragroup Conflict: A Lab in the Field Experiment in Southern Israel." Political Psychology 35(3):309335 . 


\section{Online supplementary material}

\section{A: Simple numerical example of how preference change leads to changes in behavior, other things equal}

Suppose an individual has two choices, a safe action yielding gain $y$ (e.g. income), and a risky activity (e.g. insurgency), yielding $y+B$ if successful (with probability $p$ ) and $y-F$ if unsuccessful (with probability $(1-p)$ ), where $F$ is a cost. Suppose the individual has utility of the form $U(y)=(1-\eta)^{-1} y^{1-\eta}$, where $\eta$ is a measure of their aversion to risk: the higher is $\eta$ the more risk averse the individual is, and the more they prefer the certain gain (in fact, this utility exhibits Constant Relative Risk Aversion). Define $\eta^{*}$ as the level of risk aversion that makes the individual indifferent between the stay-safe action and the risky activity:

$$
\eta^{*}: \frac{y^{\left(1-\eta^{*}\right)}}{\left(1-\eta^{*}\right)}=p \frac{(y+B)^{\left(1-\eta^{*}\right)}}{\left(1-\eta^{*}\right)}+(1-p) \frac{(y-F)^{\left(1-\eta^{*}\right)}}{\left(1-\eta^{*}\right)}
$$

If $(y, B, F, p)=(50,9.8,40,0.9)$ and then $\eta^{*}=1$. If the agent becomes more risk tolerant, then $\eta<1$, and he prefers to undertake the risky activity since he now cares less about risk, and vice versa (stay-safe action) if he becomes more risk averse, i.e. if $\eta>1$. With fixed punishments and payoffs, an individual may change their appraisal of the utility maximizing action if their risk preferences change. 


\section{B: Additional design and implementation details}

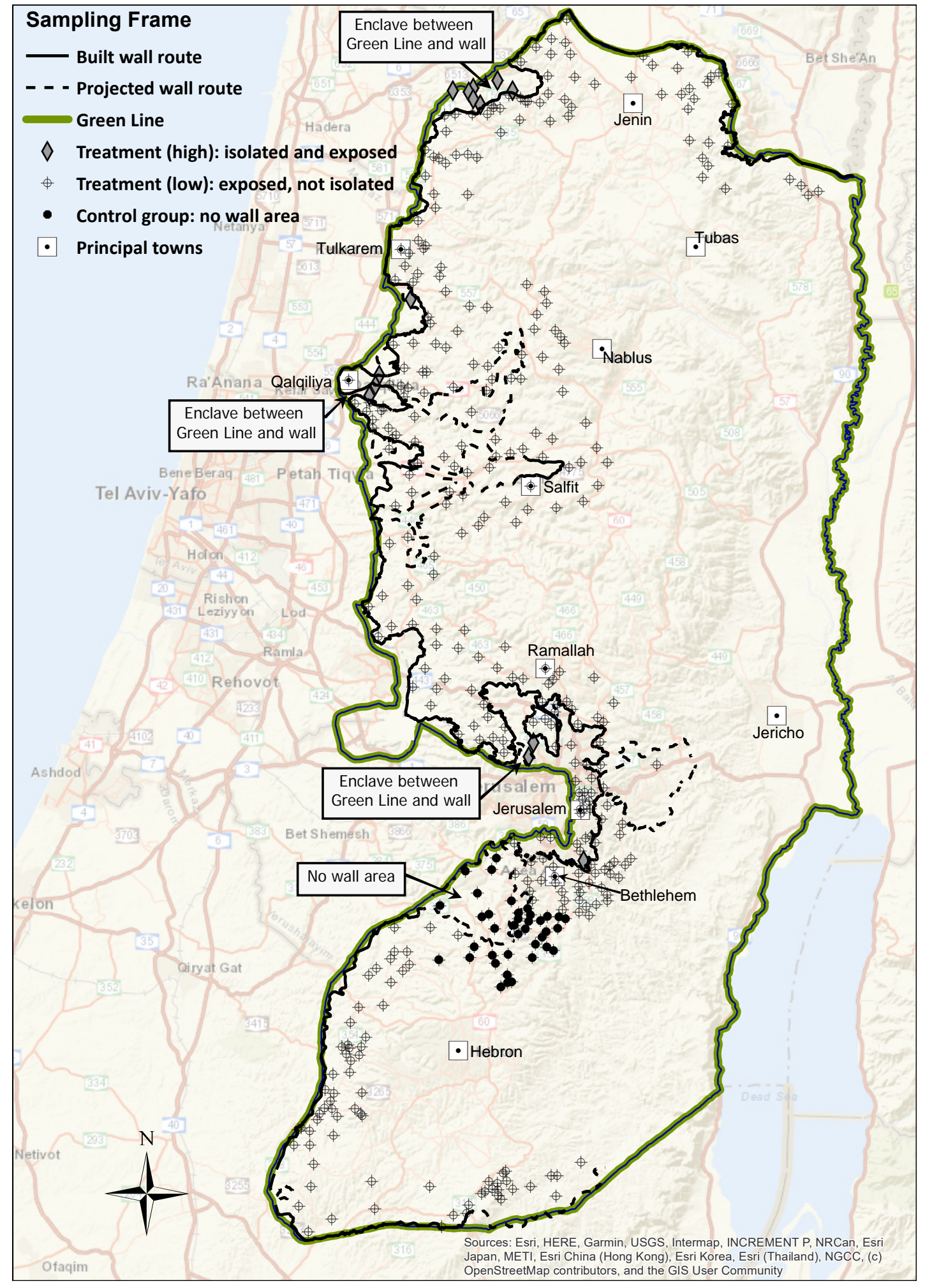

Figure B.1: Sampling frame and the wall's route 
As discussed in Section 2, the design of our questionnaire was informed by the ATF. Table B.1 records the descriptive statistics by treatment group of recall data, collected after the experiment was undertaken, on levels of anger, fear and sadness at the moment they found out the wall was built. The strength of emotions is measured on a 10-point scale. Table B.1 shows that subjects exposed to the wall report levels of anger and sadness that are significantly higher than subjects in the control group without the wall. These data provide some evidence in support of the ATF as an explanation for preference change.

\begin{tabular}{lrrr} 
Table B.1: THE WALL AND EMOTIONAL & RESPONSES \\
& Anger & Fear & Sadness \\
(i) isolated exposed & 8.541 & 6.583 & 8.895 \\
(ii) not-isolated, exposed & 8.871 & 6.115 & 8.717 \\
(iii) control & 7.619 & 6.476 & 7.833 \\
\hline Test of differences & & &
\end{tabular}

\begin{tabular}{lrlr} 
(i) vs (ii) & No diff & No diff & No diff \\
(i) vs control & Yes $(* *)$ & No diff & Yes $(* *)$ \\
(ii) vs control & Yes $(* * *)$ & No diff & Yes $(* *)$ \\
\hline
\end{tabular}

Intensity of emotions are measured over a 10-point Likert scale. Test for differences are done using F-tests in regressions controlling for clustering at the village-level: "No diff" indicates no statistically significance difference; "Yes" indicates a statistically significance differences and significance levels are represented by the stars according to the convention $*<0.1,{ }^{*}<0.05, * * *<0.01$. These results exclude individuals who show irrational behaviour in the experimental tasks. Including those individuals lead to qualitatively similar results.

Table B.2: ATtRITION AND TREATMENT GROUPS

\begin{tabular}{r|rrrrrr|r}
\hline \hline Group & Complete & Deceased & $\begin{array}{r}\text { Didn't } \\
\text { want }\end{array}$ & $\begin{array}{r}\text { Never } \\
\text { reachable }\end{array}$ & $\begin{array}{r}\text { No } \\
\text { number }\end{array}$ & $\begin{array}{r}\text { Wrong } \\
\text { number }\end{array}$ & Total \\
\hline (i) Isolated and & 51 & 1 & 1 & 9 & 2 & 9 & 73 \\
exposed & 69.86 & 1.37 & 1.37 & 12.33 & 2.74 & 12.33 & 100 \\
\hline (ii) Not-isolated, & 91 & 0 & 1 & 13 & 3 & 7 & 115 \\
exposed & 79.13 & 0 & 0.87 & 11.3 & 2.61 & 6.09 & 100 \\
\hline (iii) Not-exposed, & 55 & 0 & 0 & 8 & 0 & 7 & 70 \\
not-isolated & 78.57 & 0 & 0 & 11.43 & 0 & 10 & 100 \\
\hline Total & 197 & 1 & 2 & 30 & 5 & 23 & 258 \\
& 76.36 & 0.39 & 0.78 & 11.63 & 1.94 & 8.91 & 100 \\
\hline \hline
\end{tabular}

Notes: The table shows the number of people (and the percentages) who completed the post-experimental survey (column 'complete') and those whom we were unable to contact. For each row of the table, the first entry is the number of observations, the second entry is a percentage. 
Table B.3: SAMPle Descriptive STATistics: VARIABLES MEANS

\begin{tabular}{|c|c|c|c|c|c|c|}
\hline & \multirow{2}{*}{$\begin{array}{l}\text { Group } \\
\left(T_{\text {low }}\right) \\
\text { Not- } \\
\text { isolated, } \\
\text { exposed }\end{array}$} & \multirow{2}{*}{$\begin{array}{l}\text { Group }(C) \\
\text { Not- } \\
\text { exposed, } \\
\text { not- } \\
\text { isolated }\end{array}$} & \multirow{2}{*}{$\begin{array}{l}\text { Group } \\
\left(T_{\text {high }}\right) \\
\text { Isolated } \\
\text { and ex- } \\
\text { posed }\end{array}$} & \multicolumn{3}{|c|}{ t-tests ( $\square$ Wilcoxon rank sum test (z-value)) } \\
\hline & & & & $\begin{array}{l}\left(T_{\text {low }}\right)- \\
\left(T_{\text {high }}\right)\end{array}$ & $\begin{array}{l}(C)- \\
\left(T_{h i g h}\right)\end{array}$ & $\begin{array}{l}(C)- \\
\left(T_{\text {low }}\right)\end{array}$ \\
\hline $\mathrm{N}$ & 115 & 70 & 73 & & & \\
\hline female & 0.478 & 0.486 & 0.452 & 0.349 & 0.4 & 0.097 \\
\hline age & 37.600 & 35.840 & 35.200 & 1.351 & 0.333 & -0.975 \\
\hline grade (mean) & 4.070 & 4.014 & 4.342 & -1.352 & -1.521 & -0.288 \\
\hline no schooling $(\%)$ & 1.7 & - & 1.3 & 0.196 & . & . \\
\hline elementary (\%) & 11.3 & 10 & 6.8 & 1.011 & 0.679 & -0.277 \\
\hline preparatory $(\%)$ & 17.3 & 24.2 & 15 & 0.418 & 1.388 & 1.137 \\
\hline secondary $(\%)$ & 40.0 & 38.5 & 41.1 & -0.149 & -0.308 & -0.192 \\
\hline diploma (\%) & 7.8 & 8.5 & 8.2 & -0.096 & 0.075 & 0.180 \\
\hline bachelor $(\%)$ & 20.8 & 18.5 & 23.2 & -0.391 & -0.692 & -0.379 \\
\hline $\begin{array}{l}\text { monthly income (cate- } \\
\text { gory) }\end{array}$ & 3.574 & 3.543 & 4.466 & $-1.835 \emptyset$ & $-1.631 \downarrow$ & $-0.211 \emptyset$ \\
\hline has job & 0.774 & 0.843 & 0.712 & 0.93 & 1.89 & 1.17 \\
\hline hh size & 6.035 & 5.900 & 6.178 & -0.387 & -0.768 & -0.393 \\
\hline has child & 0.678 & 0.585 & 0.643 & 0.482 & -0.710 & -1.255 \\
\hline
\end{tabular}

The last three columns provide either t-statistics where data is continuous or ( $($ ) Wilcoxon rank sum test where data is categorical. These test the equality of means (distributions) between the high and low treatment groups, the high treatment and the control, and the low treatment and the control, respectively. 
Power calculation details: Due to the uniqueness of the research question and the field experiments, power calculations were only indicative as we could not have a strong prior concerning the effect sizes in our experiment. Power calculations assuming power $=80 \%$, confidence level $=5 \%$ and no intraclass correlation (ICC) for a range of effect sizes are reported in Table B.4, Panel A. ${ }^{43}$ The final empirical sample is made of 258 subjects (115 individuals from the exposed not-isolated group; 70 individuals from the isolated and exposed group and 73 individuals from the control group) which has the power to detect effects of between modest and medium size (following the size classification by Sawilowsky (2009) and Cohen (2013)). In our quasi-experimental design the allocation to treatment and control is outside our control and is determined by the route of the wall. Our sampling frame created symmetry by sampling participants on either side of the wall route and proposed wall route. Unavoidably, everyone in villages close to the wall is treated (with different intensities) and everyone in areas without the wall is in the control group. Given that we anticipate zero ICC, a random sample in each treatment group would have been appropriate in these circumstances. The treatment is not assigned by cluster (villages). In fact, some villages are split by the wall. Yet, for the fieldwork, we had to strike a balance between power and the budget available to us and the importance (as well as constraint) of maintaining sizable incentives in the experiments. For these budgetary reasons and the implementation logistics, we employed a two-stage cluster sampling design (and not because we expected spillover effects of the treatment or contamination of the control group as typical in cluster randomized control trial) ${ }^{44}$ For robustness, all our regressions have clustered bootstrapped standard errors to take into account the sampling design and any possible intra-cluster correlation. Power calculations assuming cluster treatment design and an ICC set at 0.01, shown in Table B.4 Panel B, suggest that our study is sufficiently powered for a medium sized effect size (we have 4-7 clusters (villages) in each group and a sample of more than 15 for each cluster).

\footnotetext{
${ }^{43}$ No intraclass correlation is a reasonable assumption because the outcomes are individual preferences and the tasks were conducted in private. We also sampled participants with the purpose of maximizing independence between observations: only one person per household, randomly selected, which avoids for example the correlation arising from assortative matching based on preferences between spouses or parent-children/siblings homogeneity.

${ }^{44}$ Stage one: a subset of clusters is randomly selected from the relevant population - villages $5 \mathrm{~km}$ either side of the wall route. Stage two: individuals are sampled randomly from the clusters using a "random route" technique, selecting every 5th house/apartment building in each selected street.
} 
Pilot and training: The experimental tasks were piloted, in English and Arabic, in various sessions with students at the University of affiliation of authors, Palestinian students at the University of Birzeit and Palestinian adults with no higher education. The explanation of the experimental tasks was accompanied by visual instruments. Five female Palestinian enumerators were trained over 1 and a half day training with the authors, during which enumerators conducted mock elicitation and interviews among themselves and with the authors.

Instructions: A particular concern was the possible sensitivity of questions involving risk in a predominantly Muslim population. Our enumerators read a consent script before the start of the interview, asking individuals if they were willing to answer a few questions and play some experimental games to understand how Palestinian make decisions in uncertain situations ${ }^{45}$ It is noteworthy that Palestinians are much less conservative than other Muslim societies and monetary games based on chance exist as TV shows (for example, the TV show 'Asandox' i.e. the box). In the tasks' explanation, we intentionally used wordings similar to Callen et al. (2014) who administered a similar risk task in Afghanistan, a much more conservative Muslim society. The instructions were translated from English to Arabic (local dialect) by a researcher familiar with the experiments and were extensively discussed between her and the authors. Time of fieldwork was planned to be amenable to people's daily schedules. Refusal to take part in the surveys was seldom and no systematic differences across areas were noted.

Incentives: All decision tasks in this paper are incentivized with real money. All subjects are paid in task 1 (risk) and task 2 (ambiguity), with disbursement of money in cash at the end of the interview. Due to the budgetary constraint, for task three (time preferences) we adopted a payoff scheme such that one single subject

\footnotetext{
${ }^{45}$ The script read "We are studying decision-making in Palestine: we are interested in understanding how Palestinians make decisions in uncertain situations of every day life. We would like to ask you some questions and play few experimental games with you. Experiments are an important tool in economic research because they help to understand how people make decisions. By participating you have the opportunity to gain some money. Would you like to participate?" The interview began with few general questions. Before the first experimental task started, participants were reminded about what the task involved and given the possibility to drop out (no one did): "Now we would like to do an experiment. Experiments are an important tool in economic research because they help to understand how people make decisions. I am going to ask you to make several choices. There is no right or wrong answer; we just would like to know the choice you like best. You may earn some money in this task. I am not asking you to make a gamble: we just want to understand how you would respond to naturally occurring risk. [... task is explained]. Before we start do you have any questions about this part of the study? Are you ready to start?".
} 
per locality is paid out a (randomly) selected decision (according to the subject's own choice). As the localities are small, this payment scheme retains the incentive compatibility. All efforts were made to generate trust of payment disbursement among the respondents. Respondents were given specific contact details and they were told the payment is guaranteed by the University of London. Respondents randomly selected the payable alternative by throwing a 12-sided die and were given a certificate to record the selected alternative and the amount to which they are entitled if selected for payment. Due to religious condemnation on the practice of loaning money with interest in Islam (which is considered as usury), we do not present individuals with the market interest they face, nor explicit information about the implied rates of return. This information is revealed in previous studies to avoid any possibility of arbitrage from the lab to the field (Harrison, Lau and Williams, 2002). It is unlikely that our subjects misrepresent their responses to invest the money in the market. We also elicit loss-aversion. The loss aversion task was not incentivised due to budgetary limitations. For consistency we exclude any discussion of these results in this paper.

Irrational behaviours: Subjects can potentially switch from one option to the other more than once in the multiple choice lists presented, signaling misapprehension of the tasks. About $6.5 \%$ of our subjects switched more than once in Task 1 (risk preferences over gain); 3.8\% in Task 2 (ambiguity attitudes); and 1.5\% in tasks 3 (time preferences). Earlier studies with similar tasks show comparable shares of multiple switching: for task 1, for example, Callen et al. (2014) document 12.7 percent of multiple switching from a sample of Afghan respondents. Another way of assessing misapprehension is to look at subjects' irrational choices in the first and last choice situation in task 1 and task 2, which involve the impossibility and certainty of winning some amount, respectively (and higher than the alternative option). 4 subjects ( $1.2 \%$ of the sample) display either of these behaviours in task 1 (risk preferences) and 3 subjects (1\% of the sample) in task 2 (ambiguity). We exclude from the analysis subjects who show either multiple switching or irrational behaviours.

Outside options: A possible confounder of our results stems from the possibility that different outside options across treatment and control groups influence the way in which subjects respond in the decision tasks. The influence of outside options on the responses in the tasks could arise if the tasks' monetary amounts, 
albeit nominally identical, were valued differently across treatment areas, or if the probabilities presented to subjects were perceived differently. Different valuations of nominally identical amounts could be reflected in economic factors such as different labour opportunities, wage levels or interest rates available in the geographic area; differences in valuations of probabilities could be reflected in subjective assessments of general probabilistic events. We have addressed each of these points and find no evidence of any differences in outside options. We now provide a summary of these findings; the tables showing these results are available from the authors on request.

To address the concern of possible differences in employment opportunities we analysed data from the Census 2007. These data show that there are no differences in the composition of the labour force between treatment and control groups. The differences in the percentages of employed, unemployed, people currently studying, housekeeping and retired, are very small in terms of Cohen's $d$-statistics. Furthermore, if there were differences between groups in the marginal utility of income, one would expect to see differences in the consumption of basic and durable goods. Again using the 2007 Census we show that there are no appreciable differences (Cohen's-d) in expenditure on basic foodstuffs like bread, fish, milk and coffee, or in more durable goods like mobile phones and satellite dishes. With regard to interest rates, Interest on money is forbidden by Islam. For this religious reason any kind of credit is usually sourced from within the family, making household size a good proxy for these opportunities. Again, we find no significant differences across treatment and control groups in household size. Another test of the impact of outside options is to check the stability of the treatment effects to control variables that proxy possible outside options, such as income, education, age and gender. Our analysis shows that the results are also robust to this test: the magnitude of the treatment effects is not affected by the addition of control variables. Finally, in order to test whether probabilities in our decision tasks are likely to have been interpreted differently in different groups we use data that we collected on probabilistic expectations to show that there are no significant differences (see Table D.17). Taken together, we find no evidence that outside options are confounding our results.

Descriptive Statistics: Table B.3 provides some sample's descriptive statistics and basic tests of balance between the two treatment groups and the control group with regard to some key socio-economic variables. None of these tests show any significant differences, with the exception of income for which differences in means 
are significant only at the 10 percent significance level. Income is controlled for in the main regressions. This provides evidence that the differences in preferences are not due to differences in the composition of these groups.

Attrition: Table B.2 is concerned with the level of attrition encountered in the follow-up telephone survey. Among the treatment and control groups there is no evidence that this process of attrition, which was somewhat minor anyway (we obtained a 76 percent response rate), would systematically bias the results since attrition is balanced across treatment and control groups.

Table B.4: Power CAlculations for estimating SAmple sizes

Panel A: Effect sizes (individual randomization design)

\begin{tabular}{lllll}
\hline & small & modest & medium & large \\
& 0.2 & 0.4 & 0.5 & 0.8 \\
\hline N per treatment & 394 & 100 & 64 & 26 \\
\hline \multicolumn{5}{l}{ Panel B: Effect sizes (clustered randomization design) } \\
\hline N clusters per treatment & 30 & 8 & 5 & 2 \\
Obs per cluster & 15 & 15 & 15 & 15 \\
Obs per treatment & 450 & 120 & 75 & 30 \\
\hline
\end{tabular}

Power calculation assumptions in Panel A: power $=80 \%$; alpha $=0.05 ; \mathrm{ICC}=0.0$.

Power calculation assumptions in Panel B: clustered randomization design, power $=80 \%$; alpha $=0.05 ; \mathrm{ICC}=0.1$. Effect size classification adopted from Sawilowsky (2009) and Cohen (2013). 


\section{C: Exogeneity and Selection Bias}

The tables in this section are referred to in Section 3 and provide evidence to support treating the location of the wall as a natural experiment. Table C.1 presents the mean and test statistics from the pre-wall data (Census 1997). Column (1) presents means for what is now 'group (i), isolated and exposed' communities; column (2) for 'group (ii), exposed, not-isolated' communities; and column (3) for 'group (iii), not-exposed' communities. The last three columns in Table C.1 report Cohen's $d$ statistics 46 The large majority of effect size statistics in Table C.1 are well below 0.2 , hence of trivial magnitude.

Table C.2 shows the proportion of migrants and emigrants that flow from each of the surveyed areas and from abroad. These percentages are small and rather similar for each area, indicating that changes in the composition of populations is unlikely to confound the causal interpretation.

Table C.3 reports the respondents' average age at marriage and average age when moving back to the location of origin in treatment and control areas. Again, these ages are practically identical.

Figure C.1 shows the age distributions over time across areas and shows that there is no statistical evidence of differences in age composition across areas that would support a claim of systematically different migration among these communities.

Finally, Table C.4 shows the duration of residence for each of the treatment areas from the surveyed sample, not the census.

\footnotetext{
${ }^{46}$ Cohen's $d$ measures 'effect size' as the scaled difference between means: $\delta=\frac{\mu_{1}-\mu_{2}}{\sigma}$, where $\mu_{1}$ and $\mu_{2}$ are the mean of group 1 and 2 respectively and $\sigma$ is the pooled sample standard deviation.
} 
Table C.1: Selection: Summary statistics from 1997 Population Census

\begin{tabular}{|c|c|c|c|c|c|c|}
\hline \multicolumn{7}{|c|}{ Population Census 1997 - individual level data } \\
\hline & (1) & (2) & (3) & Effec & t size: $\mathrm{C}$ & ohen's $d$ \\
\hline & $\begin{array}{l}\text { Group } \\
\text { (i): } T_{\text {high }} \\
\text { Exposed, } \\
\text { isolated }\end{array}$ & $\begin{array}{l}\text { Group } \\
\text { (ii): } T_{\text {low }} \\
\text { Exposed, } \\
\text { not- } \\
\text { isolated }\end{array}$ & $\begin{array}{l}\text { Group } \\
\text { (iii): } C \\
\text { Not- } \\
\text { exposed }\end{array}$ & C- $T_{\text {high }}$ & C-T $\mathbf{T}_{\text {low }}$ & $T_{\text {low }}-T_{\text {high }}$ \\
\hline $\mathrm{N}$ & 5415 & 787,561 & 15059 & & & \\
\hline female & 0.48 & 0.49 & 0.48 & 0.003 & -0.012 & 0.014 \\
\hline age $<5$ & 0.16 & 0.17 & 0.17 & 0.012 & 0.000 & 0.013 \\
\hline age $5-18$ & 0.34 & 0.33 & 0.34 & 0.005 & 0.011 & 0.005 \\
\hline age $18-65$ & 0.45 & 0.44 & 0.44 & -0.008 & -0.006 & -0.002 \\
\hline age $65+$ & 0.04 & 0.03 & 0.03 & -0.018 & -0.010 & -0.007 \\
\hline schooling (age >18) & 97 & 061 & 074 & 0121 & 0033 & 0087 \\
\hline mean & 9.27 & 9.61 & 9.74 & 0.131 & 0.033 & 0.087 \\
\hline 10th percentile & 5 & 5 & 5 & & & \\
\hline 25 th & 6 & 6 & 7 & & & \\
\hline 50 th & 9 & 9 & 10 & & & \\
\hline 75 th & 12 & 12 & 12 & & & \\
\hline 90 th & 14 & 15 & 14 & & & \\
\hline $\begin{array}{l}\text { education attainment } \\
(\%)\end{array}$ & & & & & & \\
\hline can read and write & 27 & 28 & 25.7 & -0.028 & -0.050 & 0.024 \\
\hline elementary & 29.7 & 27.4 & 26.5 & -0.071 & -0.019 & -0.051 \\
\hline preparatory & 25 & 23.4 & 27.9 & 0.063 & 0.105 & -0.038 \\
\hline secondary & 11.1 & 11.8 & 11.1 & 0.000 & -0.020 & 0.020 \\
\hline diploma & 4.5 & 4.5 & 5.3 & 0.038 & 0.040 & 0.000 \\
\hline bachelor & 2.2 & 4 & 2.8 & 0.035 & -0.057 & 0.087 \\
\hline $\begin{array}{l}\text { education attainment } \\
\text { (female, \%) }\end{array}$ & & & & & & \\
\hline can read and write & 33.3 & 33.7 & 31.1 & -0.047 & -0.055 & 0.008 \\
\hline elementary & 31.1 & 26.8 & 26.1 & -0.116 & -0.019 & -0.096 \\
\hline preparatory & 22.5 & 22 & 28 & 0.122 & 0.145 & -0.012 \\
\hline secondary & 8.5 & 10.3 & 8.6 & 0.001 & -0.057 & 0.058 \\
\hline diploma & 3.1 & 4.1 & 4.6 & 0.067 & 0.024 & 0.047 \\
\hline bachelor & 1.2 & 2.6 & 1.5 & 0.023 & -0.072 & 0.089 \\
\hline $\begin{array}{l}\text { education attainment } \\
(\text { male, \%) }\end{array}$ & & & & & & \\
\hline can read and write & 20.9 & 22.6 & 20.8 & -0.001 & -0.042 & 0.040 \\
\hline elementary & 28.3 & 27.9 & 27 & -0.029 & -0.021 & -0.008 \\
\hline preparatory & 27.4 & 24.7 & 27.7 & 0.006 & 0.069 & -0.062 \\
\hline secondary & 13.6 & 13.2 & 13.5 & -0.003 & 0.008 & -0.012 \\
\hline diploma & 5.8 & 4.9 & 6.1 & 0.012 & 0.054 & -0.040 \\
\hline bachelor & 3.3 & 5.3 & 4.1 & 0.041 & -0.052 & 0.089 \\
\hline $\begin{array}{l}\text { master and PhDs } \\
\text { marital status (\%) }\end{array}$ & 0.43 & 1.1 & 0.51 & & & \\
\hline single & 39.9 & 39.9 & 39.7 & -0.003 & -0.005 & 0.001 \\
\hline engaged & 3.2 & 1.5 & 1.1 & -0.190 & -0.034 & -0.130 \\
\hline married & 53.2 & 53.9 & 55.5 & 0.048 & 0.034 & 0.010 \\
\hline divorced & 0.4 & 0.6 & 0.6 & 0.010 & -0.007 & 0.020 \\
\hline widowed & 3.1 & 3.8 & 2.8 & -0.010 & -0.051 & 0.030 \\
\hline age at marriage & 21.9 & 21.5 & 20.4 & -0.331 & -0.212 & -0.078 \\
\hline 10th percentile & 16 & 16 & 15 & & & \\
\hline 25 th & 18 & 18 & 17 & & & \\
\hline 50 th & 21 & 21 & 20 & & & \\
\hline 75 th & 25 & 25 & 23 & & & \\
\hline 90 th & 28 & 28 & 26 & & & \\
\hline hhold size & 6.9 & 7.4 & 7.1 & 0.062 & -0.096 & 0.128 \\
\hline 10th percentile & 3 & 4 & 4 & & & \\
\hline 25 th & 5 & 5 & 5 & & & \\
\hline 50 th & 7 & 7 & 7 & & & \\
\hline 75 th & 9 & 9 & 9 & & & \\
\hline 90 th & 11 & 11 & 11 & & & \\
\hline $\begin{array}{l}\text { children }<6 \text { (propor- } \\
\text { tion hhsize) }\end{array}$ & 0.19 & 0.21 & 0.21 & 0.071 & 0.003 & 0.068 \\
\hline 10th percentile & 0 & 0 & 0 & & & \\
\hline 25 th & 0 & 0 & 0 & & & \\
\hline 50 th & 0.14 & 0.188 & 0.16 & & & \\
\hline 75 th & 0.33 & 0.33 & 0.33 & & & \\
\hline 90 th & 0.5 & 0.5 & 0.5 & & & \\
\hline
\end{tabular}




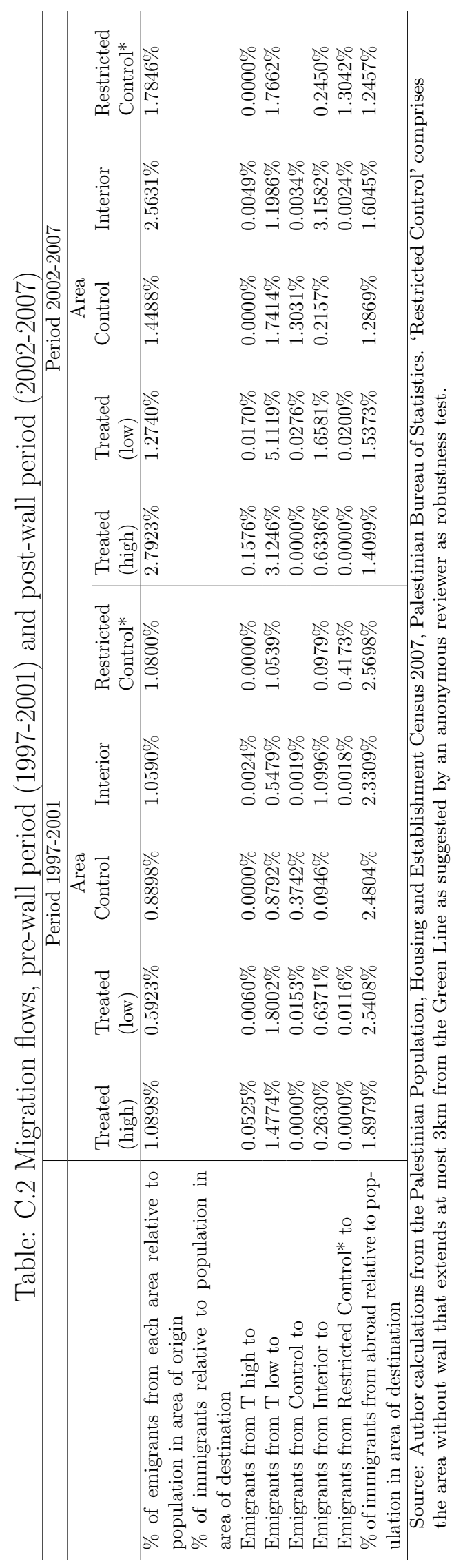




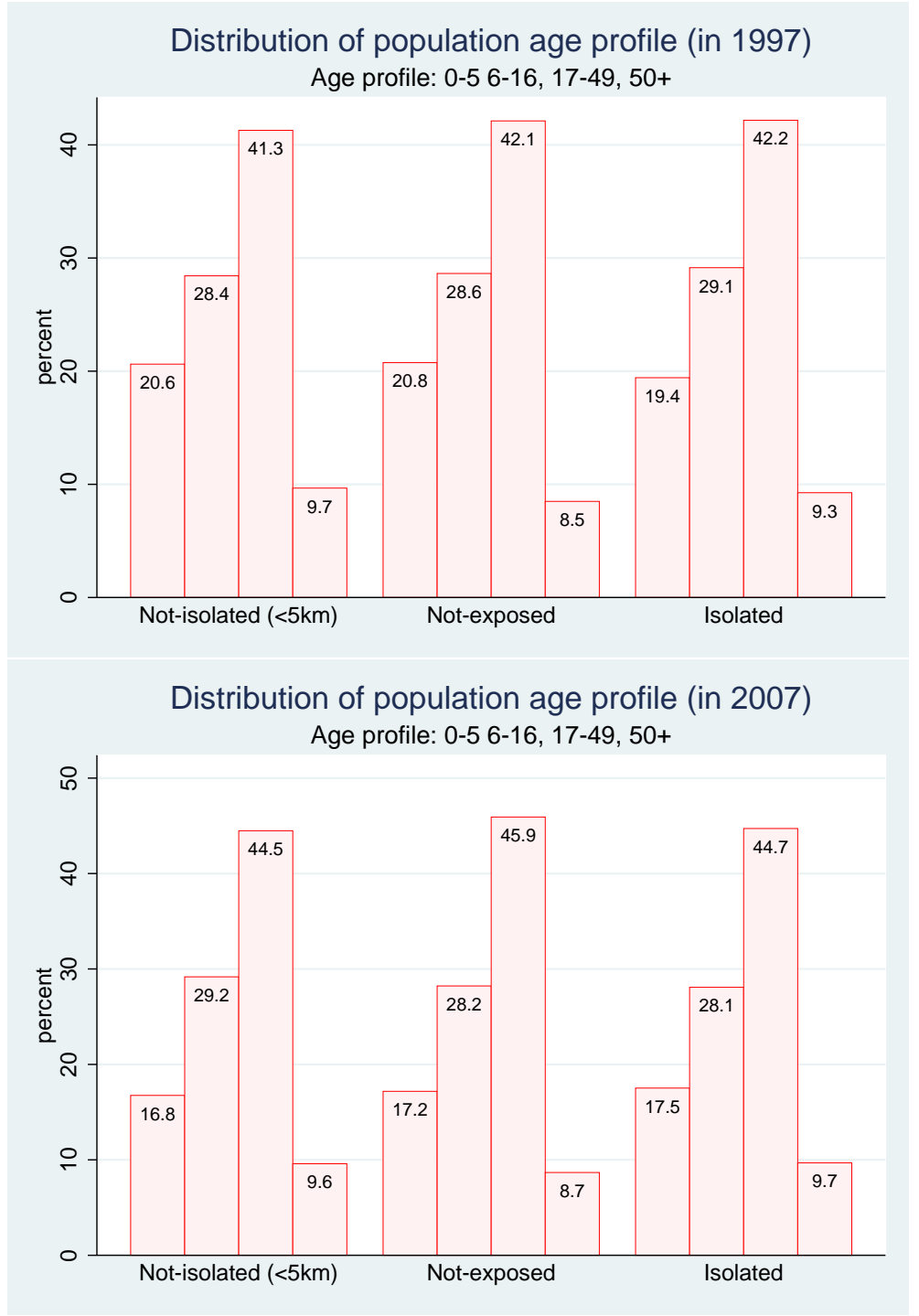

Figure C.1: Age profile (in 1997 and 2007, Population Censuses) Notes: Label 'Not-isolated' refers to group (ii), label 'Not-exposed' refers to group (iii) and label 'Isolated' refers to group (i) as defined in Table 1. 
Table C.3: Mean age (in years) of migrants by treatment and by reason for changing residence location

\begin{tabular}{l|ll}
\hline \hline & Reason: Marriage & $\begin{array}{l}\text { Reason: Returning to } \\
\text { location of origin } \\
\end{array}$ \\
& Age at marriage & Age when returning \\
\hline Treatment (high) & 21.35 & 26.23 \\
Treatment (low) & 21.27 & 26.54 \\
Control & 20.96 & 24.76 \\
\hline$\%$ of migrants & $25 \%$ & $24 \%$ \\
\hline
\end{tabular}

Source: Author calculations from the Palestinian Population, Housing and Establishment Census 2007, Palestinian Bureau of Statistics.

Table C.4 Months lived in the community, people born outside current locality, means

\begin{tabular}{rrr}
\hline \hline & Mean $\left(\mu_{i}\right)$ & T-stat: $H_{0}: \mu_{i}-\mu_{\text {group }(\text { iii })}$ \\
\hline \hline (i) isolated, exposed & 242.2 & 1.27 \\
(ii) not-isolated, exposed & 281.6 & -0.36 \\
(iii) not-exposed & 299.5 & \\
\hline \hline
\end{tabular}




\section{D: Distributions and Robustness Checks}

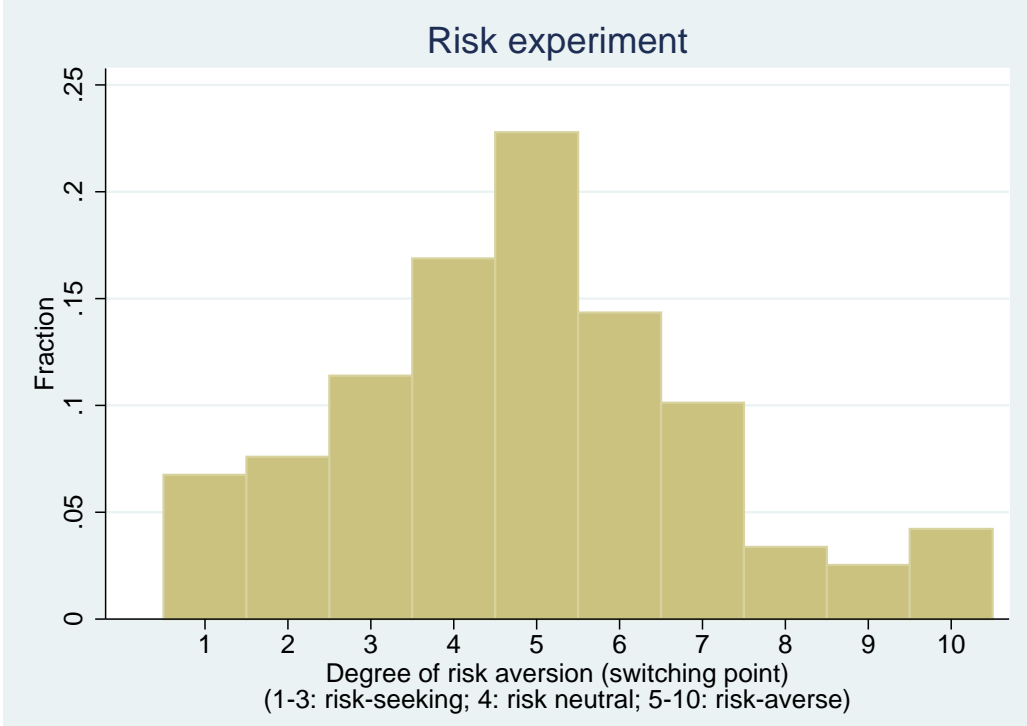

Figure D.1: Distribution of risk preferences: switching points

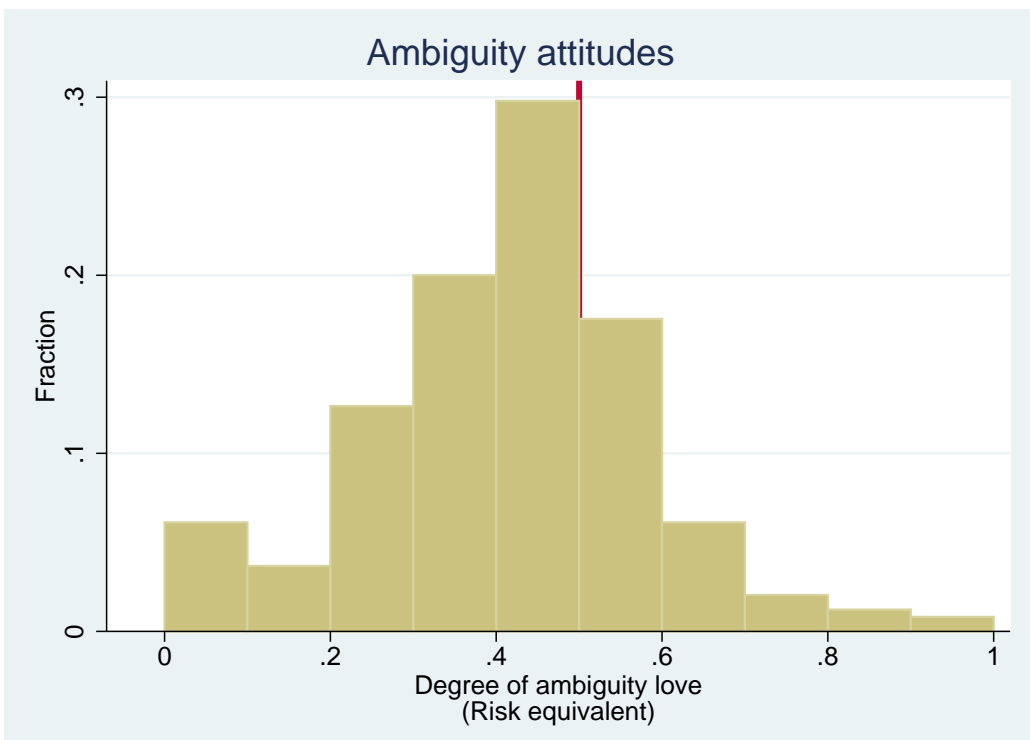

Figure D.2: Ambiguity attitudes: risk equivalent 


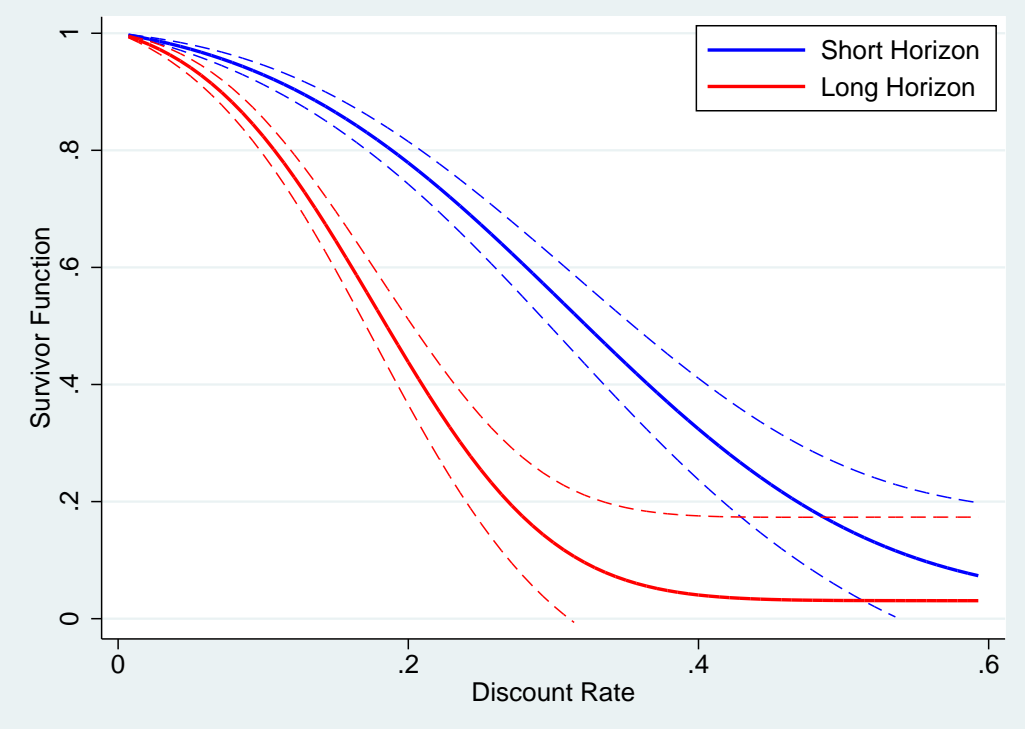

Figure D.3: Time Preferences over short and long time horizons 
Table D.1: RisK AVERSION, VILLAGE-LEVEL CONTROLS

\begin{tabular}{|c|c|c|c|c|c|}
\hline & (1) & 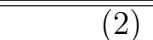 & (3) & $\overline{(4)}$ & $\overline{(5)}$ \\
\hline \multirow[t]{2}{*}{ (ii) Not-isolated, exposed } & $-0.274^{*}$ & $-0.266^{*}$ & -0.279 & -0.259 & $-0.267^{* *}$ \\
\hline & $(0.138)$ & $(0.140)$ & $(0.178)$ & $(0.177)$ & $(0.121)$ \\
\hline \multirow[t]{2}{*}{ (i) Isolated and exposed } & $-0.458^{* * *}$ & $-0.466^{* * *}$ & $-0.481^{* *}$ & $-0.460^{* *}$ & $-0.467 * * *$ \\
\hline & $(0.148)$ & $(0.143)$ & $(0.167)$ & $(0.177)$ & $(0.139)$ \\
\hline \multirow[t]{2}{*}{ age } & $0.093^{* *}$ & $0.095^{* *}$ & $0.095^{* *}$ & $0.094^{* *}$ & $0.094^{* *}$ \\
\hline & $(0.042)$ & $(0.041)$ & $(0.042)$ & $(0.042)$ & $(0.042)$ \\
\hline \multirow[t]{2}{*}{ age (squared) } & $-0.001^{*}$ & $-0.001^{*}$ & $-0.001^{*}$ & $-0.001^{*}$ & $-0.001^{*}$ \\
\hline & $(0.001)$ & $(0.001)$ & $(0.001)$ & $(0.001)$ & $(0.001)$ \\
\hline \multirow[t]{2}{*}{ female } & 0.119 & 0.121 & 0.121 & 0.120 & 0.121 \\
\hline & $(0.124)$ & $(0.126)$ & $(0.126)$ & $(0.127)$ & $(0.127)$ \\
\hline \multirow{2}{*}{ income } & -0.011 & -0.009 & -0.009 & -0.009 & -0.009 \\
\hline & $(0.019)$ & $(0.020)$ & $(0.020)$ & $(0.020)$ & $(0.020)$ \\
\hline \multirow[t]{2}{*}{ education } & 0.059 & 0.058 & 0.059 & 0.058 & 0.059 \\
\hline & $(0.047)$ & $(0.047)$ & $(0.048)$ & $(0.048)$ & $(0.047)$ \\
\hline \multirow[t]{2}{*}{ has saving } & -0.103 & -0.107 & -0.109 & -0.106 & -0.106 \\
\hline & $(0.114)$ & $(0.113)$ & $(0.115)$ & $(0.113)$ & $(0.114)$ \\
\hline \multirow[t]{2}{*}{ lost land } & & -0.056 & -0.055 & -0.058 & -0.057 \\
\hline & & $(0.124)$ & $(0.125)$ & $(0.128)$ & $(0.126)$ \\
\hline \multirow[t]{2}{*}{ altitude } & & & -0.000 & & \\
\hline & & & $(0.000)$ & & \\
\hline \multirow[t]{2}{*}{ density (pop/km2) } & & & & 0.000 & \\
\hline & & & & $(0.000)$ & \\
\hline \multirow[t]{2}{*}{ proportion PCs } & & & & & -0.000 \\
\hline & & & & & $(0.004)$ \\
\hline \multirow[t]{2}{*}{ constant } & $-1.517 * *$ & $-1.512^{* *}$ & $-1.489^{* *}$ & $-1.515^{* *}$ & $-1.502^{* *}$ \\
\hline & $(0.674)$ & $(0.683)$ & $(0.654)$ & $(0.685)$ & $(0.704)$ \\
\hline $\mathrm{N}$ & 237 & 237 & 237 & 237 & 237 \\
\hline $\mathrm{R} 2$ & 0.111 & 0.112 & 0.112 & 0.112 & 0.112 \\
\hline
\end{tabular}

Variable 'has saving' is an indicator variable coded 1 if the subject reports to have savings; the variable 'lost land' is an indicator variable coded 1 if the subject lost private land as a result of the wall construction; variable 'altitude' is the mean altitude of the village; 'density' is the village population per $\mathrm{km} 2$ in 2007; 'proportion of PCs' is the proportion of residents owning a PC in the village. Cluster-robust standard error in brackets. 
Table D.2: Ambiguity AVERsion, Village-Level CONTROlS

\begin{tabular}{|c|c|c|c|c|c|}
\hline & $(1)$ & $(2)$ & $(3)$ & $(4)$ & $(5)$ \\
\hline \multirow[t]{2}{*}{ (ii) Not-isolated, exposed } & $0.193^{*}$ & $0.200^{*}$ & 0.170 & 0.174 & $0.186^{* *}$ \\
\hline & $(0.098)$ & $(0.095)$ & $(0.111)$ & $(0.123)$ & $(0.087)$ \\
\hline \multirow[t]{2}{*}{ (i) Isolated and exposed } & $0.286^{* *}$ & $0.277^{* *}$ & $0.246^{*}$ & $0.253^{*}$ & $0.280^{* *}$ \\
\hline & $(0.111)$ & $(0.110)$ & $(0.132)$ & $(0.133)$ & $(0.096)$ \\
\hline \multirow[t]{2}{*}{ age } & -0.034 & -0.032 & -0.032 & -0.031 & -0.035 \\
\hline & $(0.023)$ & $(0.023)$ & $(0.023)$ & $(0.024)$ & $(0.022)$ \\
\hline \multirow[t]{2}{*}{ age (squared) } & 0.000 & 0.000 & 0.000 & 0.000 & 0.000 \\
\hline & $(0.000)$ & $(0.000)$ & $(0.000)$ & $(0.000)$ & $(0.000)$ \\
\hline \multirow[t]{2}{*}{ female } & -0.100 & -0.098 & -0.097 & -0.096 & -0.099 \\
\hline & $(0.112)$ & $(0.114)$ & $(0.114)$ & $(0.114)$ & $(0.114)$ \\
\hline \multirow[t]{2}{*}{ income } & -0.011 & -0.010 & -0.009 & -0.010 & -0.008 \\
\hline & $(0.019)$ & $(0.019)$ & $(0.019)$ & $(0.019)$ & $(0.019)$ \\
\hline \multirow[t]{2}{*}{ education } & $-0.100^{* *}$ & $-0.099^{* *}$ & $-0.098^{* *}$ & $-0.099 * *$ & $-0.093^{* *}$ \\
\hline & $(0.039)$ & $(0.040)$ & $(0.039)$ & $(0.040)$ & $(0.038)$ \\
\hline \multirow[t]{2}{*}{ has saving } & -0.047 & -0.054 & -0.059 & -0.055 & -0.046 \\
\hline & $(0.060)$ & $(0.066)$ & $(0.063)$ & $(0.066)$ & $(0.066)$ \\
\hline \multirow[t]{2}{*}{ lost land } & & -0.053 & -0.051 & -0.047 & -0.056 \\
\hline & & $(0.084)$ & $(0.085)$ & $(0.086)$ & $(0.085)$ \\
\hline \multirow[t]{2}{*}{ altitude } & & & -0.000 & & \\
\hline & & & $(0.000)$ & & \\
\hline \multirow[t]{2}{*}{ density (pop/km2) } & & & & -0.000 & \\
\hline & & & & $(0.000)$ & \\
\hline \multirow[t]{2}{*}{ proportion PCs } & & & & & -0.004 \\
\hline & & & & & $(0.003)$ \\
\hline \multirow[t]{2}{*}{ constant } & $1.476^{* * *}$ & $1.472^{* * *}$ & $1.521^{* * *}$ & $1.473^{* * *}$ & $1.611^{* * *}$ \\
\hline & $(0.386)$ & $(0.392)$ & $(0.417)$ & $(0.400)$ & $(0.391)$ \\
\hline $\mathrm{N}$ & 245 & 245 & 245 & 245 & 245 \\
\hline $\mathrm{R} 2$ & 0.104 & 0.106 & 0.107 & 0.107 & 0.110 \\
\hline
\end{tabular}

The variable description is in notes to Table D.1. Cluster-robust standard error in brackets. 


\section{Table D.3: Time Preferences - Entire SAmple}

\begin{tabular}{rrr}
\hline & Short-horizon & Long-horizon \\
\hline (ii) Not-isolated, exposed & -0.062 & $-0.243^{* *}$ \\
& $(0.116)$ & $(0.105)$ \\
& -0.059 & $-0.423^{* * *}$ \\
(i) Isolated and exposed & $(0.125)$ & $(0.114)$ \\
& $0.574^{* * *}$ & $0.299^{* * *}$ \\
female & $(0.087)$ & $(0.081)$ \\
& $-0.013^{* * *}$ & -0.002 \\
& $(0.004)$ & $(0.003)$ \\
grade & $0.155^{* * *}$ & $0.114^{* * *}$ \\
& $(0.035)$ & $(0.030)$ \\
income & $0.047^{* *}$ & -0.005 \\
& $(0.019)$ & $(0.017)$ \\
Modified task & $0.268^{*}$ & $-0.744^{* * *}$ \\
& $(0.157)$ & $(0.156)$ \\
risk aversion & $-0.225^{* * *}$ & $-0.362^{* * *}$ \\
& $(0.047)$ & $(0.043)$ \\
\hline $\mathrm{N}$ & 1645 & 1652 \\
\hline
\end{tabular}

The regression include data from subjects answering a version of the time preference task with 10 pairwise choices.

\section{Robustness}

This section presents additional robustness tests.

Conflict exposure. - Previous research suggests that exposure to violence alters preferences (Voors et al., 2012). A possible confounder of our results is that past experiences of violence related to the Israeli-Palestinian conflict drive the observed differences rather than the experience of the wall. We exploit our survey questionnaires to test both direct and indirect exposure to conflict. Table D.4 (for risk preferences), Table D.5 (for ambiguity preferences) and Table D.6 (for time preferences, long horizon) provide evidence against this alternative explanation. The main results are not affected by the inclusion of conflict exposure measures, which include experiencing detention or physical injury due to the conflict, having a household member detained or injured due to the conflict, being displaced and index measures of conflict exposure experienced personally or by a family member. The conflict exposure proxies are not significantly associated with preferences, suggesting that conflict does not affect preferences directly. Table D.8 shows that including interactions terms between conflict experience and wall exposure does not change the overall findings, although there is some costs in terms of estimates precision. Overall, conflict exposure does not seem to affect preferences directly in this context. 
Selective migration. - As we discussed earlier, migrants may have different preferences than non-migrants. Because of the permit regime in place in isolated areas, migration is minimal and, if few cases occurred, took place before the wall was built. This is confirmed in our data and in the Population Census data discussed in Section 3. Here we provide additional tests of selective migration by testing whether the main results are driven by subjects who moved residence. To do so, we include an indicator variable of whether the subject was born outside the sampled villages in our regressions (Table D.7). The differences in preferences in subjects exposed to the wall remain significant. This suggests that differences in preferences across groups are not driven by selective migration 47

Additional robustness checks. - Income shocks may affect preferences directly. All our regressions control for the respondent's income. Note that if it was negative income shocks driving our results we should have observed a decrease in risk tolerance, as risk tolerance usually increases in income. Instead, we observe the opposite. In this section, we present results addressing six additional concerns for the main results. First, it may be that behavior in the field experiments is affected by the context of enforced limited mobility which may have affected pre-wall social networks. Plausibly, the wall has altered the transaction cost of traveling for the isolated group. Social networks are well known to provide collective insurance and losses in this insurance function could well affect behavior in other risky situations. Using visits to family members in the interior of the West Bank (further than 10km from the location of residence) as a proxy for social networks, we find no significant differences in family visits depending on wall exposure (Table D.9) Under the assumption that there was no difference in visits before the wall, this evidence does not

\footnotetext{
${ }^{47}$ One may also be concerned that contact with the Israelis, a Western society, may have some influence on values and preferences. Further analysis shows that our results are robust to the exclusion of subjects who report working in Israel or Israeli settlements in our sample. In the general population, contact with Israelis is rare: using information from the 2007 Census data, the shares of the population in these communities who work in Israel are low and similar across groups: $1.02 \%$ in group (i), 'isolated and exposed' communities; $2.04 \%$ in group (ii), 'not-isolated, but exposed' communities; $1.30 \%$ in group (iii), communities without wall. These percentages were also small before the wall construction and similar across community groups, hence it is unlikely that our results are explained by some forms of contact or exposure to Israel (according to the Census 1997 data, the shares of the population working in Israel were $11.1 \%$ in group (i), $9.9 \%$ in group (iii), $6.4 \%$ in group (ii). )
} 
support the hypothesis that the transaction costs have dramatically altered social networks.

Second, very religious respondents could have systematically biased responses to the risk and ambiguity decision tasks because the risky urns might have been seen as gambling. Overall, the issue of association between the proposed tasks and gambling did not emerge as a problem in the pilot phase nor one that was reported by enumerators. In an additional decision task involving a choice between flipping a coin for a hypothetical prize or loss or not playing, $10 \%$ of subjects preferred not to play indicating religious motives. We use this information as a proxy for religiosity in order to test whether more religious people are systematically more risk-averse (tolerant)/ ambiguity-averse (loving) than other subjects. We observe no differences in their elicited preferences (see Table D.10). We also estimate a Simultaneous Equation Model to take into account the possibility that potential common factors jointly explain risk and ambiguity preferences (see Table D.15). The results maintain.

Third, multiple switching and irrational behaviors may be an indicator of misapprehension of the games and we exclude those subjects from the main analysis. This exclusion poses a problem if attrition is systematically related to wall exposure as we would measure preferences on a biased sample of rational respondents. Columns 1-3 in Table D.11 show no significant differences in attrition depending on treatment status. It may be that experiencing episodes of conflict may have generated cognitive difficulties which manifest in irrational behavior in the decision tasks. Column 4 in Table D.11 shows that conflict exposure is not related to irrational behavior.

Fourth, previous studies have found that subjects making sequential decisions may be influenced by prior outcomes. One example is the 'house-money effect' whereby one observes increases in risk-taking following prior gains (Thaler and Johnson, 1990). Table D.12 shows that gains in task 1 (risk) have not affected decisions in task 2 (ambiguity).

Fifth, it has been argued that subjective probability of risk may change after experiencing adverse life events (e.g. Malmendier and Nagel, 2011). The role of beliefs in constructing subjective probability is irrelevant in our risk tasks where probabilities are given and well-defined. However, one may argue that if the wall influences probability assessments systematically, then this may influence responses in the ambiguity task where probability are not defined. In order to test for dif- 
ferences in probability assessments by groups, we collected information on beliefs about a variety of uncertain life outcomes: future job loss (in the next 12 months); job insecurity, i.e. the probability of losing a job and not finding an equivalent one (Manski, 2004); life expectancy; expected out-of-pocket medical expenses and expectation on future standards of living. Table D.13 shows regression of subjective expectations in various domains of life on dummies for each treatment group. We find no significant differences in expectations across various domains of life. These findings lend some support to the view that the wall had not affected the way people form subjective probabilities.

Finally, since we have a limited number of villages, we check the robustness of our results to alternative methods of inference. These tests are shown in Table D.14. We use randomisation inference and compute the p-values of the treatment effect between isolated communities and communities without wall by simulating all possible random assignments of the treatment and calculate the p-value under the sharp null hypothesis that the treatment effect is zero for all observations. The difference between treated and control communities remains significant for risk preferences (p-value 0.024) and ambiguity preferences (p-value 0.08) and becomes noisier for time preferences (p-value 0.21 ). We also check the robustness of our treatment effects to Wild-bootstrap-t clustering of the standard errors as suggested in Cameron et al. (2008) and the p-value from regressions using village-averages (adjusted for individual covariates, as suggested in Angrist and Pischke, 2009). 
Table D.4: RISK AVERSION AND CONFLICT EXPOSURE

\begin{tabular}{|c|c|c|c|c|c|c|c|c|}
\hline & (1) & (2) & (3) & (4) & (5) & $\overline{(6)}$ & (7) & (8) \\
\hline (ii) Not-isolated, & $-0.261^{*}$ & $-0.264^{*}$ & $-0.261^{*}$ & $-0.260^{*}$ & $-0.266^{*}$ & $-0.266^{*}$ & $-0.265^{*}$ & $-0.263^{*}$ \\
\hline exposed & $(0.147)$ & $(0.145)$ & $(0.139)$ & $(0.146)$ & $(0.146)$ & $(0.141)$ & $(0.142)$ & $(0.140)$ \\
\hline (i) Isolated and & $-0.469 * *$ & $-0.461^{* *}$ & $-0.470 * * *$ & $-0.461^{* * *}$ & $-0.449 * * *$ & $-0.457 * * *$ & $-0.456^{* *}$ & $-0.457^{* * *}$ \\
\hline exposed & $(0.163)$ & $(0.158)$ & $(0.149)$ & $(0.154)$ & $(0.150)$ & $(0.153)$ & $(0.155)$ & $(0.151)$ \\
\hline injured & -0.189 & & & & & & & \\
\hline detained & $(0.175)$ & $\begin{array}{r}-0.065 \\
(0.191)\end{array}$ & & & & & & \\
\hline hh injured & & & $\begin{array}{r}-0.089 \\
(0.088)\end{array}$ & & & & & \\
\hline hh detained & & & & $\begin{array}{r}0.027 \\
(0.118)\end{array}$ & & & & \\
\hline displaced & & & & & $\begin{array}{r}-0.210 \\
(0.180)\end{array}$ & & & \\
\hline saw violence & & & & & & $\begin{array}{r}-0.077 \\
(0.102)\end{array}$ & & \\
\hline conflict exposure (indiv) & & & & & & & $\begin{array}{r}-0.057 \\
(0.123)\end{array}$ & \\
\hline conflict exposure (hhold) & & & & & & & & $\begin{array}{r}-0.058 \\
(0.123)\end{array}$ \\
\hline $\mathrm{N}$ & 237 & 237 & 237 & 237 & 237 & 237 & 237 & 237 \\
\hline $\mathrm{R} 2$ & 0.114 & 0.110 & 0.111 & 0.109 & 0.114 & 0.110 & 0.110 & 0.110 \\
\hline Controls & yes & yes & yes & yes & yes & yes & yes & yes \\
\hline
\end{tabular}

The dependent variable is a (ordinal) categorical variable of risk preferences where the higher value indicates greater risk-aversion. The variable 'conflict exposure (indiv)' is an indicator variable equals to 1 if the individual has personally experienced an injury, displacement or witnessed violence. The variable 'conflict exposure (hhold)' is an indicator variable equals to 1 if the individual has had a member of the household injured or detained. Controls include age, age squared, gender, income, education level. Cluster-robust standard errors in brackets. 
Table D.5: Ambiguity AVERSION AND CONFLICT EXPOSURE

\begin{tabular}{|c|c|c|c|c|c|c|c|c|}
\hline & (1) & (2) & (3) & $(4)$ & $(5)$ & (6) & $(7)$ & $(8)$ \\
\hline \multirow[t]{2}{*}{ (ii) Not-isolated, exposed } & $0.193^{*}$ & $0.196^{*}$ & $0.194^{*}$ & $0.206^{*}$ & $0.197^{*}$ & $0.198^{*}$ & $0.197^{*}$ & 0.191 \\
\hline & $(0.103)$ & $(0.103)$ & $(0.104)$ & $(0.111)$ & $(0.104)$ & $(0.107)$ & $(0.104)$ & $(0.109)$ \\
\hline \multirow[t]{2}{*}{ (i) Isolated and exposed } & $0.293^{* *}$ & $0.287^{* *}$ & $0.288^{* *}$ & $0.278^{* *}$ & $0.281^{* *}$ & $0.281^{* *}$ & $0.283^{* *}$ & $0.278^{* *}$ \\
\hline & $(0.109)$ & $(0.111)$ & $(0.112)$ & $(0.115)$ & $(0.112)$ & $(0.115)$ & $(0.114)$ & $(0.117)$ \\
\hline injured & $\begin{array}{r}0.177 \\
(0.139)\end{array}$ & & & & & & & \\
\hline detained & & $\begin{array}{r}0.080 \\
(0.100)\end{array}$ & & & & & & \\
\hline hh injured & & & $\begin{array}{r}0.033 \\
(0.089)\end{array}$ & & & & & \\
\hline hh detained & & & & $\begin{array}{r}0.073 \\
(0.129)\end{array}$ & & & & \\
\hline displaced & & & & & $\begin{array}{r}0.076 \\
(0.174)\end{array}$ & & & \\
\hline saw violence & & & & & & $\begin{array}{r}0.093 \\
(0.114)\end{array}$ & & \\
\hline conflict exposure (indiv) & & & & & & & $\begin{array}{r}0.031 \\
(0.108)\end{array}$ & \\
\hline conflict exposure (hhold) & & & & & & & & $\begin{array}{r}0.137 \\
(0.132)\end{array}$ \\
\hline $\mathrm{N}$ & 245 & 245 & 245 & 245 & 245 & 245 & 245 & 245 \\
\hline $\mathrm{R} 2$ & 0.111 & 0.105 & 0.104 & 0.107 & 0.105 & 0.107 & 0.104 & 0.112 \\
\hline Controls & yes & yes & yes & yes & yes & yes & yes & yes \\
\hline
\end{tabular}

The dependent variable is a (ordinal) categorical variable of ambiguity preferences (averse, neutral, tolerant) with higher value indicating ambiguity aversion. The variable 'conflict exposure (indiv)' is an indicator variable equals to 1 if the individual has personally experienced an injury, displacement or witnessed violence. The variable 'conflict exposure (hhold)' is an indicator variable equals to 1 if the individual has had a member of the household injured or detained. Controls include age, age squared, gender, income, education level. Cluster-robust standard errors in brackets. 
Table D.6: PATIEnCE AND CONFLiCT EXPOSURE

\begin{tabular}{|c|c|c|c|c|c|c|c|c|}
\hline & (1) & $(2)$ & (3) & (4) & $(5)$ & $(6)$ & $(7)$ & $(8)$ \\
\hline (ii) Not-isolated, exposed & $\begin{array}{r}-0.279^{* *} \\
(0.114)\end{array}$ & $\begin{array}{r}-0.289^{* *} \\
(0.115)\end{array}$ & $\begin{array}{r}-0.295^{* * *} \\
(0.113)\end{array}$ & $\begin{array}{r}-0.305^{* * *} \\
(0.115)\end{array}$ & $\begin{array}{r}-0.290^{* *} \\
(0.114)\end{array}$ & $\begin{array}{r}-0.286^{* *} \\
(0.115)\end{array}$ & $\begin{array}{r}-0.274^{* *} \\
(0.115)\end{array}$ & $\begin{array}{r}-0.283^{* *} \\
(0.114)\end{array}$ \\
\hline (i) Isolated and exposed & $\begin{array}{r}-0.477^{* * *} \\
(0.126)\end{array}$ & $\begin{array}{r}-0.477^{* * *} \\
(0.125)\end{array}$ & $\begin{array}{r}-0.509^{* * *} \\
(0.125)\end{array}$ & $\begin{array}{r}-0.478^{* * *} \\
(0.125)\end{array}$ & $\begin{array}{r}-0.487^{* * *} \\
(0.125)\end{array}$ & $\begin{array}{r}-0.482^{* * *} \\
(0.126)\end{array}$ & $\begin{array}{r}-0.476^{* * *} \\
(0.126)\end{array}$ & $\begin{array}{r}-0.481^{* * *} \\
(0.125)\end{array}$ \\
\hline injured & $\begin{array}{r}0.037 \\
(0.126)\end{array}$ & & & & & & & \\
\hline detained & & $\begin{array}{r}0.165 \\
(0.114)\end{array}$ & & & & & & \\
\hline hh injured & & & $\begin{array}{r}-0.128 \\
(0.081)\end{array}$ & & & & & \\
\hline hh detained & & & & $\begin{array}{c}-0.114 \\
(0.083)\end{array}$ & & & & \\
\hline displaced & & & & & $\begin{array}{r}0.137 \\
(0.134)\end{array}$ & & & \\
\hline saw violence & & & & & & $\begin{array}{r}-0.036 \\
(0.097)\end{array}$ & & \\
\hline conflict exposure (indiv) & & & & & & & $\begin{array}{r}0.050 \\
(0.103)\end{array}$ & \\
\hline conflict exposure (hhold) & & & & & & & & $\begin{array}{r}-0.030 \\
(0.089)\end{array}$ \\
\hline $\mathrm{N}$ & 1278 & 1278 & 1278 & 1278 & 1278 & 1278 & 1278 & 1278 \\
\hline
\end{tabular}

The dependent variable is a binary variable $=1$ from the period in which the later in time option is preferred. The variable 'conflict exposure (indiv)' is an indicator variable equals to 1 if the individual has personally experienced an injury, displacement or witnessed violence. The variable 'conflict exposure (hhold)' is an indicator variable equals to 1 if the individual has had a member of the household injured or detained. Controls include age, age squared, gender, income, education level, risk aversion, and dummy for periods. Cluster-robust standard errors in brackets.

Table D.7: Selective Migration

Risk aversion Ambiguity aversion Patience (long-horizon)

\begin{tabular}{rrrr}
\hline \hline (ii) Not-isolated, & $-0.207^{*}$ & $0.218^{* *}$ & $-0.249^{* *}$ \\
exposed & $(0.105)$ & $(0.099)$ & $(0.111)$ \\
(i) Isolated, & $-0.396^{* * *}$ & $0.312^{* *}$ & $-0.442^{* * *}$ \\
exposed & $(0.116)$ & $(0.110)$ & $(0.123)$ \\
born outside & $-0.293^{* *}$ & -0.105 & $-0.354^{* *}$ \\
the village & $(0.118)$ & $(0.090)$ & $(0.087)$ \\
\hline controls & Yes & Yes & Yes \\
\hline $\mathrm{N}$ & 237 & 245 & 1278 \\
$\mathrm{R} 2$ & 0.132 & 0.109 & na \\
\hline \hline
\end{tabular}

Notes: Controls include age, age squared, gender, income categories, education (and risk aversion for patience) as described in notes to Table 7. Cluster-robust standard errors in brackets. 
Table D.8: Preferences, WAll And CONFLiCt interactions

\begin{tabular}{|c|c|c|c|c|c|c|}
\hline & \multicolumn{2}{|c|}{ Risk aversion } & \multicolumn{2}{|c|}{ Ambiguity aversion } & \multicolumn{2}{|c|}{ Patience (long horizon) } \\
\hline & (1) & $(2)$ & $(3)$ & $(4)$ & $(5)$ & $(6)$ \\
\hline (ii) Not-isolated, exposed & $\begin{array}{c}-0.492524^{* *} \\
(0.227)\end{array}$ & $\begin{array}{c}-0.659895^{* *} \\
(0.226)\end{array}$ & $\begin{array}{c}0.242136 \\
(0.206)\end{array}$ & $\begin{array}{c}0.355234^{*} \\
(0.195)\end{array}$ & $\begin{array}{c}-0.342618 \\
(0.242)\end{array}$ & $\begin{array}{c}-0.305249 \\
(0.295)\end{array}$ \\
\hline (i) Isolated, exposed & $\begin{array}{c}-0.696068^{* *} \\
(0.318)\end{array}$ & $\begin{array}{c}-0.752250^{* * *} \\
(0.190)\end{array}$ & $\begin{array}{c}0.339716 \\
(0.240)\end{array}$ & $\begin{array}{c}0.333523^{*} \\
(0.198)\end{array}$ & $\begin{array}{c}-0.406340 \\
(0.255)\end{array}$ & $\begin{array}{c}-0.199502 \\
(0.315)\end{array}$ \\
\hline female & $\begin{array}{c}0.099015 \\
(0.131)\end{array}$ & $\begin{array}{c}0.115259 \\
(0.125)\end{array}$ & $\begin{array}{c}-0.092565 \\
(0.094)\end{array}$ & $\begin{array}{c}-0.102325 \\
(0.090)\end{array}$ & $\begin{array}{c}0.306566^{* * *} \\
(0.095)\end{array}$ & $\begin{array}{c}0.336790^{* * *} \\
(0.097)\end{array}$ \\
\hline age & $\begin{array}{c}0.097510^{* *} \\
(0.040)\end{array}$ & $\begin{array}{c}0.095993^{* *} \\
(0.040)\end{array}$ & $\begin{array}{c}-0.032340 \\
(0.022)\end{array}$ & $\begin{array}{c}-0.030715 \\
(0.022)\end{array}$ & $\begin{array}{c}0.044860^{*} \\
(0.024)\end{array}$ & $\begin{array}{c}0.042247^{*} \\
(0.024)\end{array}$ \\
\hline age (squared) & $\begin{array}{c}-0.001097^{* *} \\
(0.001)\end{array}$ & $\begin{array}{c}-0.001070^{*} \\
(0.001)\end{array}$ & $\begin{array}{c}0.000270 \\
(0.000)\end{array}$ & $\begin{array}{c}0.000245 \\
(0.000)\end{array}$ & $\begin{array}{c}-0.000581^{*} \\
(0.000)\end{array}$ & $\begin{array}{c}-0.000552^{*} \\
(0.000)\end{array}$ \\
\hline education & $\begin{array}{c}0.055661 \\
(0.045)\end{array}$ & $\begin{array}{c}0.058435 \\
(0.044)\end{array}$ & $\begin{array}{c}-0.102365^{* * *} \\
(0.034)\end{array}$ & $\begin{array}{c}-0.100373^{* * *} \\
(0.035)\end{array}$ & $\begin{array}{c}0.144741^{* * * *} \\
(0.036)\end{array}$ & $\begin{array}{c}0.144487^{* * *} \\
(0.035)\end{array}$ \\
\hline income & $\begin{array}{c}-0.018736 \\
(0.020)\end{array}$ & $\begin{array}{c}-0.012979 \\
(0.017)\end{array}$ & $\begin{array}{c}-0.014189 \\
(0.019)\end{array}$ & $\begin{array}{c}-0.018725 \\
(0.019)\end{array}$ & $\begin{array}{c}-0.011285 \\
(0.020)\end{array}$ & $\begin{array}{c}-0.006547 \\
(0.020)\end{array}$ \\
\hline risk aversion & & & & & $\begin{array}{c}-0.406449^{* * *} \\
(0.048)\end{array}$ & $\begin{array}{c}-0.402893^{* * * *} \\
(0.048)\end{array}$ \\
\hline conflict experience (hhold) & & $\begin{array}{c}-0.437315^{*} \\
(0.233)\end{array}$ & & $\begin{array}{c}0.263072 \\
(0.200)\end{array}$ & $\begin{array}{c}-0.039662 \\
(0.244)\end{array}$ & \\
\hline conflict (hhold) X group (ii) & & $\begin{array}{c}0.563198^{*} \\
(0.301)\end{array}$ & & $\begin{array}{c}-0.235917 \\
(0.232)\end{array}$ & $\begin{array}{c}0.080459 \\
(0.275)\end{array}$ & \\
\hline conflict (hhold) X group (i) & & $\begin{array}{c}0.417208 \\
(0.271)\end{array}$ & & $\begin{array}{c}-0.086362 \\
(0.237)\end{array}$ & $\begin{array}{c}-0.101583 \\
(0.291)\end{array}$ & \\
\hline conflict experience (ind) & $\begin{array}{c}-0.280564 \\
(0.291)\end{array}$ & & $\begin{array}{c}0.076518 \\
(0.203)\end{array}$ & & & $\begin{array}{c}0.121575 \\
(0.286)\end{array}$ \\
\hline conflict (ind) X group (ii) & $\begin{array}{c}0.298194 \\
(0.324)\end{array}$ & & $\begin{array}{c}-0.061774 \\
(0.240)\end{array}$ & & & $\begin{array}{c}0.054053 \\
(0.318)\end{array}$ \\
\hline conflict (ind) X group (i) & $\begin{array}{c}0.309510 \\
(0.387)\end{array}$ & & $\begin{array}{c}-0.074204 \\
(0.272)\end{array}$ & & & $\begin{array}{c}-0.336261 \\
(0.340)\end{array}$ \\
\hline Observations & 237 & 237 & 245 & 245 & 1,278 & 1,278 \\
\hline $\mathrm{R}$ squared & 0.114 & 0.124 & 0.104 & 0.117 & na & na \\
\hline
\end{tabular}

Notes: conflict exposure (indiv) is an indicator variable equals 1 if the individual has personally experienced an injury, displacement or witnessed violence. Conflict exposure (hhold) is an indicator variable equals 1 if the individual has had a member of the household injured or detained. Cluster-robust standard in brackets.

Table D.9: Changes IN SOCIAL NETWORKS

\begin{tabular}{llll}
\hline \hline \multicolumn{4}{l}{ Visits to family living in the West } \\
\hline Groups & $\mathrm{N}$ & mean & median \\
\hline (i) Isolated and exposed & 24 & 7.04 & 3 \\
(ii) Not-isolated, exposed & 48 & 11.39 & 4 \\
(iii) Not-exposed & 14 & 5.07 & 2 \\
\hline
\end{tabular}

Notes: The statistics are number of visits to family members in the West Bank mainland further than $10 \mathrm{~km}$ from the location of residence (conditional on having family members living in the West Bank mainland). 
Table D.10: Preferences And Religious motives AgAinst Gambling, mean TEST

\begin{tabular}{|c|c|c|c|}
\hline Religious motives & $\begin{array}{r}\text { Group (ii) } \\
\text { Not-isolated, } \\
\text { exposed }\end{array}$ & $\begin{array}{r}\text { Group (iii) } \\
\text { Not-Exposed } \\
\text { not-isolated }\end{array}$ & $\begin{array}{r}\text { Group (i) } \\
\text { Isolated and } \\
\text { exposed }\end{array}$ \\
\hline & \multicolumn{3}{|c|}{ Risk: (mean) switching point } \\
\hline yes & 5.55 & 4.85 & 4.6 \\
\hline no & 4.69 & 5.48 & 4.56 \\
\hline \multirow[t]{2}{*}{ T-test $\left(\mu_{n o}-\mu_{y e s}\right)$} & -1.22 & 1.26 & -0.05 \\
\hline & \multicolumn{3}{|c|}{ Ambiguity: (mean) switching point } \\
\hline yes & 5 & 4.88 & 5.33 \\
\hline no & 4.48 & 5.01 & 4.37 \\
\hline T-test $\left(\mu_{n o}-\mu_{\text {yes }}\right)$ & -1.4 & 0.19 & -1.29 \\
\hline
\end{tabular}

Table D.11: ATTRITION FROM EXPERIMENTAL TASKS

\begin{tabular}{|c|c|c|c|c|}
\hline \multicolumn{5}{|c|}{ Dependent Var.: displayed irrational behaviour in at least one task $(=1)$} \\
\hline (ii) Not-isolated, exposed & $\begin{array}{l}-0.073 \\
(0.055)\end{array}$ & $\begin{array}{l}-0.078 \\
(0.055)\end{array}$ & $\begin{array}{l}-0.080 \\
(0.056)\end{array}$ & $\begin{array}{l}-0.080 \\
(0.056)\end{array}$ \\
\hline (i) Isolated, exposed & $\begin{array}{l}-0.090 \\
(0.058)\end{array}$ & $\begin{array}{l}-0.090 \\
(0.058)\end{array}$ & $\begin{array}{l}-0.095 \\
(0.058)\end{array}$ & $\begin{array}{l}-0.095 \\
(0.058)\end{array}$ \\
\hline female & & $\begin{array}{l}-0.058 \\
(0.041)\end{array}$ & $\begin{array}{l}-0.057 \\
(0.041)\end{array}$ & $\begin{array}{l}-0.059 \\
(0.046)\end{array}$ \\
\hline age & & $\begin{array}{l}0.003 \\
(0.002)\end{array}$ & $\begin{array}{l}0.003 \\
(0.002)\end{array}$ & $\begin{array}{l}0.003 \\
(0.002)\end{array}$ \\
\hline grade & & & $\begin{array}{l}0.018 \\
(0.017)\end{array}$ & $\begin{array}{l}0.018 \\
(0.017)\end{array}$ \\
\hline conflict exposure & & & & $\begin{array}{l}-0.012 \\
(0.054)\end{array}$ \\
\hline constant & $\begin{array}{l}0.186^{* * *} \\
(0.047)\end{array}$ & $\begin{array}{l}0.118 \\
(0.079)\end{array}$ & $\begin{array}{l}0.028 \\
(0.109)\end{array}$ & $\begin{array}{l}0.036 \\
(0.113)\end{array}$ \\
\hline $\mathrm{N}$ & 258 & 258 & 258 & 258 \\
\hline $\mathrm{R} 2$ & 0.012 & 0.028 & 0.032 & 0.032 \\
\hline F-test of joint significance & 1.256 & 1.634 & 1.423 & 1.254 \\
\hline
\end{tabular}

The dependent variable is a indicator variable equal to one for respondents switching multiple times or showing irrational behaviour in at least one of the tasks (the two behaviours are considered together because the low number of observations precludes a separate analysis for each task). Conflict exposure is an indicator equals to 1 if the individual has personally experienced an injury, detention, displacement or witnessed violence related to the conflict with the Israelis. OLS coefficients, robust standard errors in parentheses. 
Table D.12: EXPERIMENTAL BIAS

\begin{tabular}{rrrr}
\hline \hline \multicolumn{4}{c}{ Dep. Var: ambiguity switching point } \\
\hline & $\begin{array}{r}\text { Group (ii) } \\
\text { Not-isolated, } \\
\text { exposed }\end{array}$ & $\begin{array}{r}\text { Group (iii) } \\
\text { Not-exposed, } \\
\text { not-isolated }\end{array}$ & $\begin{array}{r}\text { Group (i) } \\
\text { Isolated and } \\
\text { exposed }\end{array}$ \\
\hline payment 30 & -0.127 & 0.427 & 0.083 \\
& $(0.000)$ & $(0.603)$ & $(0.522)$ \\
payment 90 & -0.327 & 0.239 & 0.452 \\
& $(0.404)$ & $(0.525)$ & $(0.558)$ \\
constant & $4.727^{* * *}$ & $4.727^{* * *}$ & $4.235^{* * *}$ \\
& $(0.307)$ & $(0.457)$ & $(0.454)$ \\
\hline $\mathrm{N}$ & 107 & 67 & 71 \\
$\mathrm{R} 2$ & 0.006 & 0.008 & 0.015 \\
F test & 0.342 & 0.251 & 0.502 \\
\hline \hline
\end{tabular}

Notes: Payment 30/90 indicates the amount won (in sheckels) in Task 1. The excluded category is zero payment.

Table D.13: EXPECTATIONS AND WALL EXPOSURE

\begin{tabular}{c|cccccc}
\hline \hline & $(1)$ & $(2)$ & $(3)$ & $(4)$ & $(5)^{*}$ & $(6)^{*}$ \\
& job loss & job insecurity & life expect70 & medical expenses & improve child life & improve life style \\
\hline (ii) Not-isolated, & -5.936 & -1.912 & 3.834 & -8.387 & 0.147 & 0.225 \\
exposed & $(7.437)$ & $(7.799)$ & $(4.990)$ & $(5.125)$ & $(0.213)$ & $(0.182)$ \\
(i) Isolated, & -8.728 & -5.352 & 0.396 & -6.609 & $0.277^{*}$ & 0.125 \\
exposed & $(8.496)$ & $(8.604)$ & $(4.705)$ & $(5.333)$ & $(0.155)$ & $(0.191)$ \\
constant & $39.0714^{* * *}$ & $25.928^{* * *}$ & $47.403^{* * *}$ & $71.038^{* * *}$ & - & - \\
& $(6.858)$ & $(7.626)$ & $(4.089)$ & $(4.517)$ & & 194 \\
$\mathrm{~N}$ & 196 & 196 & 190 & 184 & 196 & - \\
$\mathrm{R} 2$ & 0.010 & 0.005 & 0.007 & 0.016 & - & - \\
\hline \hline
\end{tabular}

Notes: (1) Job loss is the percentage chance of loosing the job (conditional on working). (2) Job insecurity is the combination of the chance of loosing a job and not finding an equivalent one, as in Manski (2004). (3) Life expectancy is the chance to reach the age of 70 (respondent with inconsistent responses are excluded). (4) Medical expenses is the chance of spending more than NIS 500 in out-of-pocket medical expenses over the next year. (5) The dependent variable is a categorical measure indicating the expectations about children's standard of living when they will have the age of the respondent in comparison to the respondent's nowadays standard of living (from 1, much lower, to 5 , much higher). (6) The dependent variable is a categorical variable indicating the expectation of the respondent's standard of living in ten years time being lower, the same or higher. Coefficients in (1) to (4) are estimated using OLS. *:(5) and (6) are estimated using ordered probit. A probit on a two-category variable reclassification in (6) leads to qualitatively the same results.

Table D.14: RAndomization InFEREnCE AND STANDARD ERRORS ROBUSTnESS CHECKS

\begin{tabular}{|c|c|c|c|}
\hline \multicolumn{4}{|c|}{ TREATMENT EFFECT (ISOLATED VS. CONTROL) P-VALUES } \\
\hline & Risk aversion & $\begin{array}{l}\text { Ambiguity Aver- } \\
\text { sion }\end{array}$ & $\begin{array}{l}\text { Time prefer- } \\
\text { ences } \\
\text { (long horizon) }\end{array}$ \\
\hline Cluster-robust & $(0.009)$ & $(0.022)$ & $(0.030)$ \\
\hline Randomisation Inference & $(0.024)$ & $(0.087)$ & $(0.210)$ \\
\hline $\begin{array}{l}\text { Wild-cluster bootstrap-t } \\
\text { (Cameron et al., 2007) }\end{array}$ & $(0.032)$ & $(0.069)$ & na \\
\hline $\begin{array}{l}\text { Covariate adjusted, WLS } \\
\text { (Angrist, 2008) }\end{array}$ & $(0.003)$ & $(0.023)$ & na \\
\hline
\end{tabular}


Table D.15: Simultaneous Equation Model Estimation

\begin{tabular}{lrr}
\hline & Risk aversion & Ambiguity \\
\hline (ii) not-isolated, exposed & $-0.243^{*}$ & $0.208^{* *}$ \\
& $(0.132)$ & $(0.102)$ \\
(i) isolated, exposed & $-0.456^{* * *}$ & $0.293^{* * *}$ \\
& $(0.145)$ & $(0.111)$ \\
female & 0.151 & -0.142 \\
& $(0.124)$ & $(0.095)$ \\
age (in years) & $0.111^{* * *}$ & $-0.040^{*}$ \\
& $(0.031)$ & $(0.024)$ \\
age (squared) & $-0.001^{* * *}$ & 0.000 \\
& $(0.000)$ & $(0.000)$ \\
income & -0.021 & -0.015 \\
& $(0.027)$ & $(0.020)$ \\
education & 0.043 & $-0.093^{* * *}$ \\
& $(0.045)$ & $(0.035)$ \\
constant & $-1.761^{* * *}$ & $1.548^{* * *}$ \\
& $(0.569)$ & $(0.437)$ \\
\hline Observations & \multicolumn{3}{c}{230} & \\
R-squared & 31.74 &
\end{tabular}

The tables estimates a system of equations for risk and ambiguity preferences. The number of observations include rational subjects in both tasks.

Table D.16: Omitted Variable Bias: Altonji (2005)/ Oster (2019) Ratios

\begin{tabular}{|c|c|c|c|c|c|}
\hline & Control set & Risk & Ambiguity & Time (short) & Time (long) \\
\hline & \multicolumn{5}{|c|}{ Altonji, Elder, TABER (2005) TEST } \\
\hline (i) isolated, exposed & as in Table 6 & {$[<0]$} & {$[<0]$} & {$[<0]$} & {$[<0]$} \\
\hline \multirow[t]{2}{*}{ (ii) not-isolated, exposed } & as in Table 6 & {$[<0]$} & {$[<0]$} & 0.786 & {$[<0]$} \\
\hline & \multicolumn{5}{|c|}{ Oster (2019) BIAS-ADJUSTED TEST } \\
\hline $\begin{array}{l}\text { (i) isolated, exposed } \\
\text { bounds for } \beta\end{array}$ & as in Table 6 & $\begin{array}{l}{[<0]} \\
{[-0.687,-0.458]}\end{array}$ & $\begin{array}{l}{[<0]} \\
{[0.285,0.832]}\end{array}$ & na & na \\
\hline $\begin{array}{l}\text { (ii) not-isolated, exposed } \\
\text { bounds for } \beta\end{array}$ & as in Table 6 & $\begin{array}{l}{[<0]} \\
{[-0.532,-0.263]}\end{array}$ & $\begin{array}{l}{[<0]} \\
{[0.197,0.539]}\end{array}$ & na & na \\
\hline \multicolumn{6}{|c|}{$\begin{array}{l}\text { The table reports the degree of selection on unobservables relative to observables which is required to } \\
\text { produce a treatment effect of zero, using the methods of Altonji, Elder and Taber }(2005) \text { and Oster }(2019) \\
\text { (the } \delta \text { in their papers). The entry }[<0] \text { indicates that the respective ratios are negative. This is because } \\
\text { the observable controls are on average positively correlated with the outcome variable and negatively } \\
\text { with the treatment, suggesting a downward bias in the OLS estimates (provided the unobservables have } \\
\text { similar correlation patterns with the outcome and the treatment as the included observables). The } \\
\text { control variables included are those presented in Table } 5 \text { of the paper. The bounds for } \beta \text { are calculated } \\
\text { according to Oster }(2019) \text {, page } 18 \text {, using the conservative assumption that the maximum explainable } \\
\text { variation is } 1\left(R_{\max }=1\right) \text { and delta }=1 \text {. Oster }(2019) \text { 's methods is tested for linear regressions and }\end{array}$} \\
\hline
\end{tabular}




\section{References cited in Appendix}

Angrist, Joshua D and Pischke, JS. 2009. "Instrumental variables in action: sometimes you get what you need". Mostly harmless econometrics: an empiricist's companion, pp. 113-220.

Callen, Michael and Isaqzadeh, Mohammad and Long, James D. and Sprenger, Charles. 2014. "Violence and Risk Preference: Experimental Evidence from Afghanistan." The American Economic Review 104(1): 123-148.

Cohen, J. 2013. "Statistical power analysis for the behavioral sciences". Routledge.

Cameron, A Colin and Gelbach, Jonah B and Miller, Douglas L. 2008. "Bootstrapbased improvements for inference with clustered errors." The Review of Economics and Statistics 90(3): 414-427.

Malmendier, Ulrike and Nagel, Stefan. 2011. "Depression Babies: Do Macroeconomic Experiences Affect Risk Taking?". The Quarterly Journal of Economics: 126(1): 373-416.

Manski, Charles F. 2004. "Measuring Expectations". Econometrica 72(5): 1329-1376.

Oster, E., 2019. "Unobservable selection and coefficient stability: Theory and evidence". Journal of Business \& Economic Statistics, 37(2), pp.187-204.

Sawilowsky, Shlomo S. 2009. "New Effect Size Rules of Thumb". Journal of Modern Applied Statistical Methods. Vol. 8 : Issue 2 , Article 26.

Thaler, Richard H. and Johnson, Eric J. 1990. "Gambling with the House Money and Trying to Break Even: The Effects of Prior Outcomes on Risky Choice". Management Science 36(6): 643-660. 
Voors, M. and Nillesen, E. and Verwimp, P. and Bulte, E. and Lensink, R. and van Soest, D. 2012. "Violent Conflict and Behavior: A Field Experiment in Burundi". The American Economic Review 102(2): 941-964. 